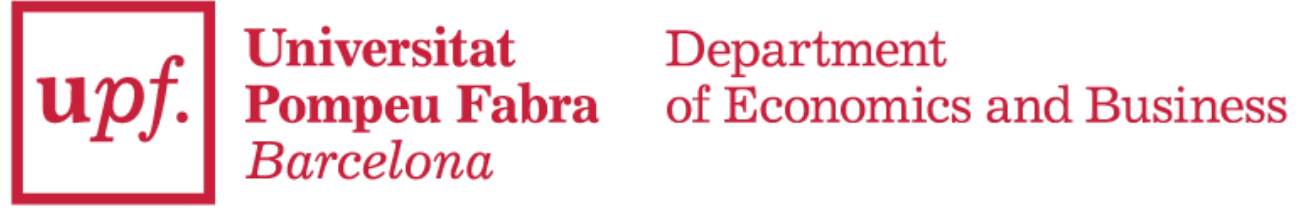

Economics Working Paper Series

Working Paper No. 1534

\title{
Income-Induced expenditure switching
}

\author{
Rudolfs Bems \\ Julian di Giovanni
}

August 2016 


\title{
Income-Induced Expenditure Switching*
}

\author{
Rudolfs Bems \\ University of Tokyo
}

\author{
Julian di Giovanni \\ Universitat Pompeu Fabra \\ Barcelona GSE \\ CREI and CEPR
}

August 20, 2016

\begin{abstract}
This paper shows that an income effect can drive expenditure switching between domestic and imported goods. We use a unique Latvian scanner-level dataset, covering the 2008-09 crisis, to document several empirical findings. First, expenditure switching accounted for one-third of the fall in imports, and took place within narrowly-defined product groups. Second, there was no corresponding within-group change in relative prices. Third, consumers substituted from expensive imports to cheaper domestic alternatives. These findings motivate us to estimate a model of non-homothetic consumer demand, which explains two-thirds of the observed expenditure switching. Estimated switching is driven by income, not changes in relative prices.
\end{abstract}

\section{JEL Classifications: F1; F3; F4}

Keywords: Expenditure switching; relative price adjustment; crisis; income effect

${ }^{*}$ We are grateful to Rimi Baltic, Anders Alexanderson, Vyacheslav Dombrovsky, and Anders Paalzow for helping us acquire the scanner-level data. We would like to thank the editor, two anonymous referees, Cristina Arellano, Paula Bustos, Oli Coibion, Fabrizio Coricelli, Giancarlo Corsetti, Doireann Fitzgerald, Jessie Handbury, Jonathan Heathcote, Rob Johnson, Andrei Levchenko, Philippe Martin, Akito Matsumoto, Isabelle Mejean, Maurice Obstfeld, Franck Portier, Steven Phillips, Jay Shambaugh, Mick Silver, Alan Taylor, Jaume Ventura, Kei-Mu Yi, and seminar participants at the 2013 AEA Meetings, Bank of England, Bank of Latvia, CREI, ECB Conference on "Heterogeneity in Currency Areas and Macroeconomic Policies," ESSIM 2014, European Commission Conference on "Current Account Imbalances and International Financial Integration," FRB of Governors, IMF, Minneapolis Fed, 2013 NBER Summer Institute IFM Meetings, Philadelphia Fed International Trade Workshop, University of Tokyo, Swiss National Bank and SNB-CEPR Conference on "Exchange Rates and External Adjustment" for helpful comments. Marola Castillo and Jair Rodriguez provided superb research assistance. This work was partly carried out while Bems was visiting the Bank of Latvia and the Stockholm School of Economics in Riga. Hospitality of both institutions is gratefully acknowledged. All remaining errors are our own. E-mail (URL): rudolfs.bems@gmail.com (http://sites.google.com/site/rudolfsbems), julian.digiovanni@upf.edu (http://julian.digiovanni.ca). 


\section{Introduction}

The exchange rate plays a central role in discussions of external balance adjustments across countries. When prices are sluggish to adjust, a currency depreciation provides a potentially fast way to reduce domestic prices, relative to foreign ones, which in turn increases demand for domestic goods at home and abroad and leads to expenditure switching. Therefore, a common policy prescription for countries with fixed exchange rate systems, and facing balance of payments crises, has been to devalue their exchange rates in order to facilitate external adjustment. The international macroeconomics theory underlying this conventional external adjustment channel assumes that a change in a country's income affects the consumption of domestic and foreign goods proportionally, so that a relative price change is the only source of expenditure switching (see, for example, Engel, 2003; Obstfeld and Rogoff, 2007).

This paper revisits the relationship between relative prices, income changes, and expenditure switching during a balance of payments crisis. We exploit a unique item-level dataset to demonstrate that income-induced expenditure switching is needed to understand the data, and that a model with non-homothetic preferences better matches the observed expenditure switching than a constant elasticity of substitution (CES) model, which is typically used in international macroeconomics.

We focus on the 2008-09 balance of payment crisis in Latvia, during which the country defied the conventional policy prescription and maintained its exchange rate pegged to the euro. ${ }^{1}$ To the surprise of many economists, within 2 years from the outset of the crisis, a $20 \%$ of GDP trade deficit was reduced to balanced trade and GDP growth resumed (see Figure 1). The bulk of the external adjustment took place on the import side, as the share of imports in GDP declined from $65 \%$ in 2007 to $45 \%$ in $2009 .^{2}$ The adjustment in aggregate relative prices was subdued, as Latvia's real exchange rate remained broadly unchanged over 2008-11. ${ }^{3}$ Latvia's experience has generated recent interest because it is one of the few examples where a large external adjustment was achieved faster than expected and without a nominal devaluation or a significant adjustment in relative prices,

\footnotetext{
${ }^{1}$ See Blanchard et al. (2013) for a forensic account of Latvia's boom, bust, and recovery over 2000-13.

${ }^{2}$ The crucial role of import compression in driving the adjustment was also observed in the other Baltic states, as well as the Eurozone periphery countries (Kang and Shambaugh, 2013b).

${ }^{3}$ As panel (c) in Figure 1 demonstrates, the main driver of Latvia's real exchange rates over the period was the nominal effective exchange rate, which, in fact, appreciated by 5\% during 2008-09 because of "third-country" exchange rate movements (i.e., the euro was appreciating viz. Latvia's non-euro trade partners). Meanwhile, wages in manufacturing were cut by $7 \%$ initially, but quickly recovered to pre-crisis levels (Blanchard et al., 2013).
} 
thus potentially shedding light on a successful adjustment process in a monetary union, and particularly in the southern periphery countries of the Eurozone who also faced an appreciated real exchange rate and price rigidity.

This paper zooms in to the microeconomic level to better understand what drove the adjustment in imports. First, we quantify how much expenditure switching took place between domestic and imported goods. Second, we explore the margins - across or within product groups - at which expenditure switching and relative price changes took place. Finally, we ask whether the observed relative price changes can explain the observed expenditure switching through the lens of the conventional theory and whether the income effect had a role to play.

We measure relative price and consumption changes across goods using a scanner-level dataset on food, beverages and other supermarket items, covering the 2006Q2-2011Q1 period. These data provide both prices and quantities at the individual item level, and crucially identify the country origin of each item, and detailed product groups to which items belong to. The key advantage of the dataset is that it allows for measurement of expenditure switching and relative prices with internally consistent data, which we find to be representative of aggregate expenditure and price movements in the food sector. It is also important to note that a similar exercise using available trade and macroeconomic data is not possible, since such data do not identify quantities and prices of comparable domestic and imported goods in final consumption.

We find that during the crisis period expenditures on imports fell by $26 \%$, while overall expenditures on food contracted by $18 \%$, so that expenditure switching from imported to domestic goods accounted for one-third of the total fall in imports in the scanner dataset. ${ }^{4}$ We then use the item-level dimension of the data to present two main findings. First, the majority of the expenditure switching was driven by substitution between goods within narrowly defined product groups. Second, there was no corresponding change in the relative price of imports within product groups. The change in the relative price of imports - a modest $3.8 \%$ rise - was driven almost entirely by changes in prices across product groups.

The observed expenditure switching within product groups without a corresponding relative price adjustment presents a puzzle. Why did consumers switch to domestic substitute items within product groups, if such items did not become less expensive than their imported counterparts? Our proposed answer focuses on the shift in consumed item mix

\footnotetext{
${ }^{4}$ The other two-thirds was due to a proportional fall in domestic and imported goods in response to the crisis-induced fall in aggregate income.
} 
within product groups, as summarized by a third empirical finding: consumers substituted from expensive imported items to cheaper domestic alternatives. We find that within narrowly defined product groups imported items are on average $28 \%$ more expensive than comparable domestic items, and that consumers substituted towards cheaper similar items, irrespective of origin, during the crisis. This substitution generated expenditure switching from imported to domestic items without any adjustment in relative prices.

Motivated by the empirical findings, we set up a demand-side model of the economy to formally quantify contributions of relative prices and the substitution towards cheaper goods to the observed expenditure switching, and to link consumers' substitution behavior to the observed fall in aggregate income. We model an expenditure allocation problem of a representative consumer. Given item-level prices and the crisis-induced fall in income, a consumer decides how to allocate expenditures across and within product groups. The consumer's choice depends on relative prices as well as an income-driven demand for quality. With quality considerations switched off, the model is a conventional CES demand system.

We estimate the model parameters in a panel regression setting using disaggregated item-level data, and control for a host of potential factors that might otherwise bias the estimation results, as well as running instrumental variable regressions on subsets of the data. We then use the estimated parameters to construct a predicted aggregate measure of expenditure switching over the sample period. The results are quite striking. First, the conventional CES model performs poorly: though the estimated price elasticities are similar to available estimates in the literature, and are statistically significant, the model's predicted expenditure switching does not match the switching observed in the data, particularly during the crisis episode. Second, the non-homothetic model is better able to match observed expenditure switching during the crisis - it captures two-thirds of what is observed in the data. We further find that the income channel, not relative prices, drives expenditure switching in the non-homothetic model.

Our findings are consistent with the flight from quality hypothesis put forth in Burstein et al. (2005), who present facts on consumer shopping patterns during the 2001 Argentinean crisis. They argue that ignoring consumers' substitution towards lower quality (thus cheaper) goods introduces a bias in measured CPI, and relative price movements. Besides complementing Burstein et al. (2005)'s findings, we are able to shed further light on the impact of this "flight" by identifying a switch from foreign to domestic items and linking the flight to changes in income. The absence of a large devaluation, combined with the drastic fall in income, makes the Latvian crisis episode an ideal case for identifying the 
income-induced channel of expenditure switching.

Although the results in this paper are based on scanner-level data for a particular sector for one country, they may speak to broader issues in international macroeconomics. First, the international trade literature has documented that poorer countries tend to be net importers of higher quality goods across all sectors of the economy (see, e.g., Hummels and Klenow, 2005; Hallak, 2006; Feenstra and Romalis, 2014). Therefore, for these countries, the income effect may play an important role in external adjustment, regardless of exchange rate movements. Given the recent crisis in the Eurozone, there has indeed been an adjustment in the periphery countries who were subject to large negative income shocks, and the income-induced expenditure switching is a possible channel to help explain this phenomenon. Second, there is also a large literature documenting the Alchian and Allen (1964) effect, which posits that traded goods tend to be higher quality than domestic ones - commonly referred to as "shipping the good apples out" (see Hummels and Skiba, 2004, for some recent empirical evidence). If this is indeed the case, then income-induced expenditure switching may be a more general phenomenon affecting external adjustment across countries. Furthermore, the proposed channel may have asymmetric effects across countries given different income levels. For example, a rich country like the United States may in fact be a net importer of lower quality goods, so expenditure switching may go in the opposite direction than what we find for Latvia. Third, in support of the flight from quality hypothesis, some recent work has pointed to a fall in the quality composition of large EU countries' exports during the "Great Trade Collapse." 5 Such work, however, remains silent about implications for expenditure switching, as there is no matching data for domestic goods.

Our work can be related to several strands of existing literature. We contribute to the large literature in international macroeconomics on external adjustment. This literature is comprised of an extensive list of theoretical studies on expenditure switching and the role of exchange rate policy (see Engel (2003) for a review; and Burstein et al. (2007), Kehoe and Ruhl (2009), Mendoza (2005), Obstfeld and Rogoff (2007) for work studying sudden stop episodes). Previous work has also suggested that besides relative prices the extensive margin can have an impact on the external adjustment (e.g., see Krugman, 1989; Corsetti et al., 2013). The non-homothetic channel we introduce in our work is distinct from this

\footnotetext{
${ }^{5}$ See, for example, Berthou and Emlinger (2010) and Esposito and Vicarelli (2011). Though, focusing on U.S. import data, Levchenko et al. (2011) reject the hypothesis that the fall in imports was skewed toward higher quality goods. Meanwhile, in the context of an emerging market, Chen and Juvenal (2015) use detailed micro data on wine exports from Argentina and measures of wine quality to show that there was a fall in the quality of exports during the GTC.
} 
mechanism. Furthermore, we show empirically that our results are robust to extensive margin considerations.

This paper also contributes to the extensive literature that measures the adjustment in relative prices (see Burstein and Gopinath, 2014, for a recent survey). ${ }^{6}$ Our contribution to this literature is two-fold. First, we provide direct empirical evidence for expenditure switching, which can be linked to a relative price adjustment. To the best of our knowledge, such evidence at the microeconomic level is non-existent. ${ }^{7}$ Second, we contribute to the scarce literature on external adjustment under a fixed exchange rate regime, which makes our study particularly relevant for the current policy debate on the external adjustment process in a currency union. ${ }^{8}$

Our findings also emphasize the relevance of non-homothetic preferences in macroeconomics, and complement a rapidly growing literature on trade and income inequality that models non-homotheticities in the demand for quality. ${ }^{9}$ We are not the first to study macroeconomic implications of non-homotheticities in consumption. For example, nonhomothetic preferences are widely used in the literature on growth and structural change. ${ }^{10}$ We instead focus on crises (i.e., large economic fluctuations). Diaz Alejandro (1965) is an early study of how income effects can affect external rebalancing. ${ }^{11}$ He investigates how consumption behavior differences between wage and non-wage earners affect the demand of different sectors' imports. In the absence of data on income heterogeneity, we instead focus on the large change in aggregate income and explore its implications for demand of high/low priced items in narrowly-defined product groups.

The rest of the paper is organized as follows. Section 2 describes the data. Section 3 presents the paper's three main empirical findings about expenditure switching and the accompanying price adjustment. Section 4 employs an estimated demand model to more formally quantify the contribution of relative price changes and income effects in explaining the observed expenditure switching. Section 5 concludes.

\footnotetext{
${ }^{6}$ Of particular note, work by Parsley and Popper (2006) studies relative price movements under a fixed exchange rate regime (Hong Kong), and recent papers by Berka et al. (2012) and Cavallo et al. (2014) contrast real exchange rate adjustments in and outside the Eurozone.

${ }^{7}$ Of course, there is a long-standing literature that estimates import elasticities, which has more recently highlighted the importance of heterogeneity across sectors. See, Imbs and Méjean (2009) and Feenstra et al. (2014) for two recent contributions. There is also the literature studying the possibility of a "J-Curve" in the trade balance following an exchange rate change, which follows the classic work of Magee (1973).

${ }^{8}$ See Farhi et al. (2013) for recent work studying alternative ways of generating devaluations in the absence of exchange rate flexibility.

${ }^{9}$ For example, Hallak (2006), Fajgelbaum et al. (2011), Fajgelbaum and Khandelwal (2013), Faber (2014).

${ }^{10}$ See Herrendorf et al. (2014) for a recent survey.

${ }^{11}$ We thank Chang-Tai Hsieh for bringing Diaz Alejandro's work to our attention.
} 


\section{Data Description}

The analysis is based on detailed scanner-level data, which contain monthly information on quantities sold and the average price level charged for 13-digit UPC (universal product code) items sold by one of Latvia's largest retailers - Rimi. ${ }^{12}$ The data are collected across three types of stores that the retailer owns and runs: a chain of 'Hypermarkets' $(\mathrm{H})$, a chain of typical 'Supermarkets' (S), and a chain of 'Discounter' (D) stores. ${ }^{13}$ We treat items sold at each store as distinct. Data for each type of store are aggregated across the respective type's sales-per-item across the country, so there is no geographical distinction by type of store. The provided data cover the six-year period May 2006-May 2011, which spans Latvia's boom, bust, and the beginning of its subsequent recovery. The coverage of goods is primarily for food and beverages $(\mathrm{F} \& \mathrm{~B})$, but the dataset also contains other consumer goods typically available at supermarkets, such as toiletries. Besides quantity and price information, the dataset provides information on the unit of measure (e.g., KG), the net content of each UPC item and a short item description with an accompanying retailer assigned 'material' code.

The retailer also provides 2-, 3-, and 4-digit classifications of the items into product groups. An example of a 2-digit product group would be 'hot drinks,' which at the 3digit level is further broken down into 'tea,' 'coffee,' and 'cacao.' The 3-digit group 'tea' is further broken down at the 4-digit level into types of tea. For example, there is 'unflavored black tea,' 'flavored black tea,' 'herbal tea,' 'fruit tea,' etc. Since this is not a widely used product classification, it is useful to contrast it to the standard combined nomenclature (CN8) classification of trade flows. We find that for majority of product groups the 4-digit supermarket product classification is comparable to or even narrower than the CN8 trade flow classification at the most detailed 8-digit level. Thus, 4-digit supermarket scanner product groups are based on very narrow product definitions.

The 13-digit UPC is crucial for the analysis because it allows us to identify the domestic/foreign origin of each item. In particular, the first three digits of the bar code identify the country in which the label was applied for. Because Latvia is a small market, foreign suppliers usually do not relabel their goods in Latvian. Instead, imported items carry a source country label or a label intended for a larger destination market. This allows us to

\footnotetext{
${ }^{12}$ Rimi Baltic is a major retail operator in the Baltic states based in Riga, Latvia. It is a subsidiary of Swedish group ICA. Rimi Baltic operates 235 (as of year 2013) retail stores in Estonia (83 stores), Latvia (113 stores) and Lithuania (39 stores) and has distribution centers in each country.

${ }^{13}$ The $\mathrm{S}$ and $\mathrm{H}$ stores carry a wider variety of goods than D stores, and the same 13-digit UPC item can vary in price across the three types of stores.
} 
use the item's label to identify domestic/foreign origin. However, for items of foreign origin the label does not necessarily identify the country of production. ${ }^{14}$

An alternative approach to identifying the item's origin suggests that the UPC is a valid proxy. We zoom in on the domestic/imported origin for a subset of 4-digit product groups that explicitly group items by origin (e.g., imported and domestic beer). Such product groups account for $11.6 \%$ of total $\mathrm{F} \& \mathrm{~B}$ expenditures in our sample, $6.2 \%$ of which are identified as domestic and $5.4 \%$ as foreign. We find that for product groups that are identified as domestic, $97.3 \%$ of expenditures carry local UPCs. For product groups that are identified as imported, $97.2 \%$ of expenditures carry foreign UPCs. This suggests that for a small market, such as Latvia, the UPCs can correctly identify the domestic/foreign origin for more than $97 \%$ of expenditures. We also note that, despise the significantly reduced sample size, the main findings of this paper remain unchanged if this alternative identification of origin is used.

\subsection{Data Cleaning and Consolidation}

As with any large micro dataset, data cleaning is needed. First, given our focus on expenditure switching between domestic and imported goods, we are forced to drop all 'store products,' for which we cannot identify their origin. Such items are produced/labeled by the retailer, with the bulk falling into specific product groups such as 'store bake,' 'fruits and berries,' and 'vegetables and root crops.' The 13-digit UPC identifies such items as 'store products,' but provides no information about the origin of ingredients. 'Store products' and product groups dominated by such items account for $29 \%$ of total food expenditures in the dataset over the whole sample period. ${ }^{15}$

Second, we drop items (i) without a UPC, and (ii) with either quantity or price less or equal to zero. Imposing these two conditions left total sales virtually unchanged, decreasing them by $0.3 \%$.

We next consolidate the scanner-level data for homogeneous items. We start by consolidating data by the triplet of (i) UPC, indexed with $i$, (ii) store type $(s)$, and (iii) time period $(t)$, because in the original dataset information pertaining to a given triplet can be reported in multiple entries. The consolidation is done by summing quantities, $q_{i s t}$, and expenditures, $x_{i s t}$, over identical triplets and then re-computing item unit values from the

\footnotetext{
${ }^{14}$ For example, the UPC of a bottle of tequila produced in Mexico, but labeled for the United States, and then shipped to Latvia would identify the bottle as originating from the United States.

${ }^{15}$ We reintroduce 'store products' back into the sample when examining results that do not require information about items' origin, such as shifts in within group item mix (see Section 3.3.1).
} 
aggregated data. As a check that the data we consolidate pertain to homogeneous items, we compare prices for all identical triplets and find that in $99.7 \%$ of cases prices are indeed identical.

On some occasions the UPC is an "overly" unique identifier of homogeneous items. For example, this would be the case if an item's label is frequently updated. Two such cases are presented in the panel below, which shows data entries as they appear in the dataset before consolidation:

\begin{tabular}{|c|c|c|c|c|c|c|c|c|c|c|c|}
\hline \multirow{2}{*}{$\begin{array}{c}\text { 4-digit } \\
\text { product code }\end{array}$} & \multirow{2}{*}{$\begin{array}{l}\text { Product group } \\
\text { description }\end{array}$} & \multirow{2}{*}{$\begin{array}{c}\text { 'Material' } \\
\text { code }\end{array}$} & \multirow[b]{2}{*}{ Item description } & \multirow{2}{*}{$\begin{array}{c}\text { Net } \\
\text { content }\end{array}$} & \multirow[b]{2}{*}{ UPC } & \multicolumn{3}{|c|}{ Quantities } & \multicolumn{3}{|c|}{ Average prices } \\
\hline & & & & & & $2009 / 4$ & $2009 / 5$ & $2009 / 6$ & $2009 / 4$ & $2009 / 5$ & $2009 / 6$ \\
\hline 6439 & Other dental care eq & 404199 & DENTAL FLOSS ORAL B SATIN 25M & $25 \mathrm{M}$ & 5010622017947 & 93 & 105 & 106 & 2.04 & 2.04 & 2.04 \\
\hline 6439 & Other dental care eq & 404199 & DENTAL FLOSS ORAL B SATIN 25M & $25 \mathrm{M}$ & 5010622018258 & 20 & 5 & 9 & 2.04 & 2.04 & 2.04 \\
\hline 2101 & Fat-free milk & 211961 & MILK VALMIERA $0,5 \% 1 \mathrm{~L}$ & $1 \mathrm{~L}$ & 4750074000500 & 1331 & 640 & & 0.47 & 0.47 & \\
\hline 2101 & Fat-free milk & 211961 & MILK VALMIERA $0,5 \% 1 \mathrm{~L}$ & $1 \mathrm{~L}$ & 4750074005062 & & 994 & 2152 & & 0.47 & 0.47 \\
\hline
\end{tabular}

The items identified by the retailer's 'material' codes 404199 and 211961 have identical (i) product description, (ii) net content, (iii) average monthly prices, and (iv) producer code (identified by the first 6 digits of the UPC), but have different 13-digit UPCs. For the purpose of this paper such items can be treated as homogeneous. Motivated by this example, we consolidate data by the pair of (i) 'material' code and (ii) store type when prices are identical in all periods for overlapping pairs. This consolidation decreases the number of unique UPC-store items in our sample by $14 \%{ }^{16}$

\subsection{Summary Statistics}

Table 1 presents annual data for all products in the resulting dataset, as well as domestic and foreign goods separately. Given the sample period, we drop the last month of the sample, and define a year as May to April. So, for example, 2006 would be the year covering May 06-April 07. Looking at columns (1) and (2), one sees that the value of sales increased until 2008-09 when the crisis hit, and there is then a pick up in 2010-11 as the Latvian economy began to recover. The same pattern holds for both domestic and foreign sales. Column (3) reveals an elevated price increase during the pre-crisis boom, driven by prices of domestic goods. Once the crisis hits, there is deflation, again driven by the domestic component of food expenditures. The final column (4) reports the number of unique UPC-store items sold by the retailer each year, as well as their domestic/imported breakdown. Overall, there are 80,890 unique UPC-store items sold over the 5-year sample period, of which 26,244 are of

\footnotetext{
${ }^{16}$ This aggregation across items can be used to shed further light on the quality of the scanner-level dataset. If the UPC identifies unique items, then the multiple entries for the same UPC should all report the same 4-digit product group and have the same net content. We find that this is the case for 98.8-99.5\% of aggregated items, depending on the store type.
} 
domestic origin and the remaining 54,646 are imported.

Next, Table 2 presents summary statistics for 2-digit product groups over the whole sample period. The 'Share' column reports the share of each product group's sales viz. total sales over the period. 'Alcoholic products' make up the largest share of total sales, accounting for $14.7 \%$ of aggregate revenue. The 'Foreign Share' column measures the foreign content of a given product group. Though the food and beverage sector is generally considered a tradable sector (Berka and Devereux, 2011; Crucini et al., 2005), we find considerable heterogeneity in import intensity among product groups at this relatively high level of aggregation. Foreign contents range from as lows such as $2 \%$ ('Dairy products') to a high of $100 \%$ ('Baby foods'). While the foreign share of total sales is $40 \%$, imports account for a mere $7 \%$ of the least import-intensive quarter of food sales.

\subsection{Aggregated Scanner-Level Data and Macroeconomic Trends}

Food and beverages account for approximately $30 \%$ of total household expenditures in Latvia, ${ }^{17}$ therefore the scanner-level data cover an important component of total consumption. Furthermore, given the size of the retailer, the scanner-level dataset directy adds up to $15 \%$ of aggregate household expenditure on $\mathrm{F} \& \mathrm{~B}$ over the period. In order to draw aggregate implications from the dataset, we next compare key aggregate statistics on $\mathrm{F} \& \mathrm{~B}$ with equivalent series constructed from the scanner-level data.

First, as Figure 2 shows, the constructed aggregate price index closely mimics the official F\&B's CPI. ${ }^{18}$ Second, retail market share data, kindly provided to us by IGD Retail Analysis, show that during 2007-11 the retailer maintained a stable grocery retail market share of around 20\% (see Table 3). Further, the number of stores operated by the retailer did not vary systematically with the crisis.

Next, Figure 3 plots the total revenue of foreign products across all stores and aggregate F\&B imports used for final consumption. The two series are highly correlated, and the scanner-level data pick up the large fall in imports over the crisis period. ${ }^{19}$

Given that a sizable part in the fall of trade during the Great Trade Collapse was

\footnotetext{
${ }^{17}$ According to the Latvian CPI calculations, food has a $35 \%$ weight, but in the national income accounts data, F\&B account for $25 \%$ of household expenditures. We therefore take a simple average to arrive at the $30 \%$.

${ }^{18}$ The monthly CPI from scanner-level data is constructed using multilateral GEKS price index. For an in-depth discussion of this index see Ivancic et al. (2011).

${ }^{19}$ Aggregate F\&B imports in customs data drop more quickly than in the store data and also show a more rapid recovery. This could be due to an inventory effect (e.g., such as argued by Alessandria et al., 2010). Though interesting for future research, this finding does not impact the analysis of the current paper given that we are interested in studying the total impact of the crisis, and not the dynamics per se.
} 
due to durables, we also examine the breakdown of Latvia's annual imports between nondurable and durable goods during the boom-bust-recovery period in Table 4. Imports of food and beverages (excluding tobacco) constitute $25 \%$ of non-durable imports, which in turn make up roughly one half of total imports, and accounted for a substantial portion of total import growth over the sample period. The fall in durable imports was indeed larger than for non-durables during the crisis in 2009. However, the fall in non-durable imports was substantial (i.e., 28\%), and accounted for roughly one-third of the total fall in imports, which is consistent with what happened in the rest of the world (see Bems et al., 2013). In comparison, imports of F\&B fell by $21 \%$ in 2009 (see Figure 3), which was somewhat less than the fall in non-durables, but still of a similar magnitude. Therefore, although our scanner-level dataset covers only one sector of the economy, it is an important one, both for total private consumption and aggregate imports.

Finally, why use scanner-level data rather than more commonly available macroeconomic data to study expenditure switching? The micro-level data allow us to measure prices and expenditures on domestic and imported goods at a very disaggregate level within a single large dataset using consistent final consumer prices. In contrast, macroeconomic data would require combining data on trade flows with household expenditure data, which creates multiple issues. The main issue is that household expenditures are measured in final consumer prices and bundle together expenditures on imports with a large domestic retail margin, while trade flows are measured at the dock (Berger et al., 2009; Burstein et al., 2005). Furthermore, National Income Account data estimate expenditures indirectly (and at a relatively high level of aggregation) using infrequent surveys. Another issue is that inventories can drive a wedge between final expenditures and trade flows, especially during sudden stop episodes (Alessandria et al., 2010).

\section{Empirical Findings}

The Latvian economy experienced a sharp contraction during the sudden stop, felt across all sectors of the economy, including consumption in food and beverages. Figure 4 uses quarterly data to plot the year-on-year (y-o-y) log change in real aggregate food consumption in the scanner-level data. ${ }^{20}$ The figure depicts a classic "boom-bust" episode. Consumption was growing before the crisis, at which point it experienced a substantial drop, bottoming out at $-16 \%$ in real terms over Q4:08-Q4:09. To eliminate seasonality and provide a

\footnotetext{
${ }^{20}$ The sample begins at the second quarter of 2006, which is defined as May-July in order to maximize observations. Using y-o-y changes helps avoid seasonality issues.
} 
consistent time frame for the results reported in this paper, we label these four consecutive quarters with the largest cumulative fall in food consumption as the crisis year. Note that this is done purely for presentational convenience, as none of our main findings hinge on a specific definition of the crisis period.

The scanner-level data allow us to document three empirical findings pertaining to expenditure switching during the crisis, with a focus on the relative movements of the domestic and foreign components of consumption and prices within and across narrowly defined product groups. These findings underpin the main results of the paper, as well as motivate the modeling and estimation methodology we use below.

The three empirical findings are:

1. Expenditure switching from imported to domestic food accounted for one third of the contraction of imports during the crisis, and was driven mainly by switching between items within narrowly defined product groups.

2. The expenditure switching was accompanied by a $3.8 \%$ rise in the relative price of foreign goods to total food CPI, where the relative price change was driven almost entirely by changes in prices across product groups.

3. Within the narrowly defined product groups, consumers systematically switched from higher unit value imported items to lower unit value domestic items during the crisis, which generated expenditure switching without any adjustment in relative prices.

\subsection{Finding 1: Expenditure Switching}

We first examine the role of expenditure switching in the total fall of imports during the crisis. A contraction in imports can be linked to either an across-the-board compression in food consumption, which affects domestic and imported food proportionally, or a reallocation of food expenditures from imports towards domestic products, i.e., expenditure switching. In the scanner-level data over the Q4:08-Q4:09 period imports fell by 26\%, while total food expenditures fell by $18 \%$. Therefore, expenditure switching accounted for 8 percentage points, or one third, of the fall in imports.

An alternative way of quantifying the size of the expenditure switching is to consider a y-o-y change in the aggregate import expenditure share in quarterly data. To construct the import expenditure share from the item-level data, it is useful to introduce some notation. Define a product group $g \in\{1, \ldots, G\}$, an item $i \in I_{g}$, and expenditure share $s_{\text {igt }}$ for item $i$ in product group $g$ in period $t$, so that $\sum_{g} \sum_{i} s_{i g t}=1$. Further, denote $s_{g t}^{j}=\sum_{i \in I_{g t}^{j}} s_{i g t}$ as 
the expenditure share for a subset $j$ of items in product group $g$. With this notation we can express the expenditure share of a product group as $s_{g t}=\sum_{i \in I_{g t}} s_{i g t}$, and the aggregate expenditure share on imports as $s_{t}^{F}=\sum_{g} \sum_{i \in I_{g t}^{F}} s_{i g t}$, where $F$ refers to the subset of imported items.

The solid line in Figure 5 plots the y-o-y change in the aggregate import share, $s_{t}^{F}-s_{t-4}^{F}$, over the sample period. At the trough (i.e., Q4:09 relative to Q4:08), 3.7 cents of every euro spent on F\&B were reallocated from imports towards domestically produced food. Since the aggregate import expenditure share in the dataset is 0.40 (see Table 2), this amounts to a $9.3 \%$ fall in the import expenditure share.

Although there is entry and exit of items in the scanner-level data, we find that the adjustment at the intensive margin accounts for the bulk of the expenditure switching in Latvia (see Appendix A for details). Given the relatively short horizon of our analysis, it is not that surprising that the extensive margin does not play a large role in the crisis dynamics, as, for example, inventories may have dampened the extensive margin supply response in the short run. Furthermore, our findings are consistent with those of the recent trade collapse literature, which also finds that the extensive margin played a small role (see Bems et al., 2013, for a recent review).

We next exploit the data at both the product group and item level in order to distinguish between two sources of expenditure switching due to consumers reallocating expenditures either (i) across product groups, or (ii) between domestic and foreign items within product groups. The within margin can contribute directly to expenditure switching, as consumers substitute between similar domestic and foreign items. The across margin can contribute to expenditure switching indirectly as long as product groups have different import shares. For example, if the dairy product group is mainly composed of domestic items, while the alcohol product group has a large foreign content, then substitution from alcohol to dairy, holding all else equal, would result in aggregate expenditure switching.

Formally, define the share of imports within a product group as $\varphi_{g t}^{F} \equiv s_{g t}^{F} / s_{g t}$. Then $s_{t}^{F}=\sum_{g} s_{g t} \varphi_{g t}^{F}$, and aggregate expenditure switching between any two periods $k$ and $t$ can be decomposed into the two additive components of interest - expenditure switching within and across product groups - as follows:

$$
\begin{aligned}
s_{t}^{F}-s_{k}^{F} & =\sum_{g} s_{g t} \varphi_{g t}^{F}-\sum_{g} s_{g k} \varphi_{g k}^{F} \\
& =\underbrace{\sum_{g} s_{g k}\left(\varphi_{g t}^{F}-\varphi_{g k}^{F}\right)}_{\text {Within }}+\underbrace{\sum_{g} \varphi_{g k}^{F}\left(s_{g t}-s_{g k}\right)}_{\text {Across }}+\underbrace{\sum_{g}\left(\varphi_{g t}^{F}-\varphi_{g k}^{F}\right)\left(s_{g t}-s_{g k}\right)}_{\approx 0} .
\end{aligned}
$$


Figure 5 plots this decomposition for y-o-y changes in $s_{t}^{F}$, where a product group $g$ is defined at the narrowest 4-digit level. We find that the bulk of expenditure switching took place within the narrow sectors (dash-dot line), as consumers substituted from foreign to domestic goods, while maintaining relatively constant shares of expenditures across product groups throughout the sample. The within-switching is a crucial empirical finding that our analysis incorporates below.

To zoom in on this key expenditure switching decomposition result, Figure 6 shows the distribution of import share growth rates during the crisis period, $\varphi_{g, Q 4: 09}^{F} / \varphi_{g, Q 4: 08}^{F}$, for the 291 4-digit product groups that make up Finding 1. The histogram reveals sizable dispersion in the import share growth rates, with the share of imports contracting in twothirds of product groups. The growth rate for the median groups is $-4 \%$ and mean growth rate is $-15 \%$.

Given the structure of the scanner data, one can further investigate whether the switching within product groups is taking place predominantly across store types (e.g., buying the same UPC item at a Discounter store instead of a Supermarket), ${ }^{21}$ or across items within a given store type. A simple extension of (1), detailed in Appendix B, allows us to quantify contributions from these two substitution margins to the overall expenditure switching. Results show that more than $90 \%$ of expenditure switching took place within, rather than across, store types. This finding can be explained in terms of the potential for savings that the two substitution margins offer in the scanner data. Substituting across stores can provide savings of up to $11 \%$ for a median item. As we will show in Section 3.3, this margin of savings is a fraction of what consumers can save by substituting across items in the narrowly defined 4-digit product groups.

\subsection{Finding 2: Relative Price Adjustment}

We next examine price movements of domestic and import goods at the aggregate and product group level. In order to do so, we construct comparable price indexes across product groups from the UPC-level data on unit values and quantities. For our baseline results we construct aggregate prices using discrete Divisia (Törnqvist) price indexes. ${ }^{22}$ The overall price index for $\mathrm{F} \& \mathrm{~B}$ is

$$
\Delta \ln P_{t}=\sum_{g} \sum_{j} \sum_{i \in I_{g t}^{j}} w_{i g t} \Delta \ln p_{i g t},
$$

\footnotetext{
${ }^{21}$ See Coibion et al. (2015).

${ }^{22}$ The findings of this paper are robust to the use of alternative price index definitions, such as the multilateral GEKS, Fisher or Laspeyres, in the construction of aggregate prices.
} 
where $p_{i g t}$ is the unit value of item $i$ in product group $g, w_{i g t} \equiv 1 / 2\left(s_{i g t}+s_{i g t-1}\right)$ is a corresponding expenditure-based weight, and $j=\{D, F\}$ sorts items by source (Domestic/Foreign) within each product group. Narrower price indexes of interest are computed as components of the overall price index. For example, price changes in product group $g$ are

$$
\Delta \ln P_{g t}=\frac{1}{\sum_{j} \sum_{i \in I_{g t}^{j}} w_{i g t}} \sum_{j} \sum_{i \in I_{g t}^{j}} w_{i g t} \Delta \ln p_{i g t},
$$

and price changes for imported items in product group $g$ are

$$
\Delta \ln P_{g t}^{F}=\frac{1}{\sum_{i \in I_{g t}^{F}} w_{i g t}} \sum_{i \in I_{g t}^{F}} w_{i g t} \Delta \ln p_{i g t} .
$$

In order to link the relative price adjustment to our measure of expenditure switching, we define the aggregate relative price of imports as $P_{t}^{F} / P_{t}$, where $P_{t}^{F}$ and $P_{t}$ are, respectively, price indexes for aggregate imports and aggregate food consumption. The solid line in Figure 7 plots the y-o-y change in $\ln \left(P_{t}^{F} / P_{t}\right)$. The relative price increases by $3.8 \%$ y-o-y during the crisis period (Q4:08-Q4:09), and by $5.3 \%$ from trough to peak. ${ }^{23}$

As with expenditure switching, it is instructive to decompose the change in the relative price into across and within product-group components. First, note that the (log) relative price can be written as a weighted sum of product-group relative prices:

$$
\ln \frac{P_{t}^{F}}{P_{t}}=\sum_{g} \frac{w_{g t}^{F}}{w_{t}^{F}} \ln \frac{P_{g t}^{F}}{P_{t}}=\sum_{g} \frac{w_{g t}^{F}}{w_{t}^{F}}\left(\ln \frac{P_{g t}^{F}}{P_{g t}}+\ln \frac{P_{g t}}{P_{t}}\right),
$$

where $w_{g t}^{F} / w_{t}^{F}=\sum_{i \in I_{g t}^{F}} w_{i g t} /\left(\sum_{g} \sum_{i \in I_{g t}^{F}} w_{i g t}\right)$ is the import share of group $g$ in total imports. We can then express the growth rate of the relative price between periods $k$ and $t$ as

$$
\begin{aligned}
\ln \frac{P_{t}^{F}}{P_{t}}-\ln \frac{P_{k}^{F}}{P_{k}} & =\sum_{g} \frac{w_{g t}^{F}}{w_{t}^{F}}\left(\ln \frac{P_{g t}^{F}}{P_{g t}}+\ln \frac{P_{g t}}{P_{t}}\right)-\sum_{g} \frac{w_{g k}^{F}}{w_{k}^{F}}\left(\ln \frac{P_{g k}^{F}}{P_{g k}}+\ln \frac{P_{g k}}{P_{k}}\right) \\
= & \underbrace{\sum_{g} \frac{w_{g k}^{F}}{w_{k}^{F}}\left(\ln \frac{P_{g t}^{F}}{P_{g t}}-\ln \frac{P_{g k}^{F}}{P_{g k}}\right)}_{\text {Within }}+\underbrace{\sum_{g} \frac{w_{g k}^{F}}{w_{k}^{F}}\left(\ln \frac{P_{g t}}{P_{t}}-\ln \frac{P_{g k}}{P_{k}}\right)}_{\text {Across }} \\
& +\underbrace{\sum_{g}\left(\frac{w_{g t}^{F}}{w_{t}^{F}}-\frac{w_{g k}^{F}}{w_{k}^{F}}\right) \ln \frac{P_{k}^{F}}{P_{k}}}_{\approx 0} .
\end{aligned}
$$

\footnotetext{
${ }^{23}$ Note that the relative price increase in imported food contrasts with the overall appreciation of the CPIbased real exchange rate as discussed in footnote 3 above. These contrasting movements can be reconciled by the fact that food exports (i.e., imports in our scanner data) are not included in CPI in source countries. In addition, imports from non-euro countries are likely invoiced in euros, limiting the effect of exchange rate movements on import prices.
} 
In Figure 7, again using 4-digit product groups, one can see that the increase in the relative price of imports was almost entirely driven by price movements across product groups (dash line). Within-product group relative prices (dash-dot line) did not exhibit sizable systematic deviations. ${ }^{24}$ Our findings with regard to the price adjustment are the opposite of what occurred for expenditure shares, where switching took place within, not across product groups. From the conventional macroeconomic theory standpoint these contrasting findings present a puzzle: why are consumers buying more domestic varieties even though domestic items are not becoming less expensive than their foreign counterparts?

To shed further light on this puzzle, Figure 8 zooms in on the two components of the within price adjustment in (5): group-by-group change in the relative price of imports, $\ln \left(P_{g t}^{F} / P_{g t}\right)-\ln \left(P_{g k}^{F} / P_{g k}\right)$, and the corresponding product group's share in total imports, $w_{g k}^{F} / w_{k}^{F} \cdot{ }^{25}$ We find the absence of a systematic import price adjustment during the crisis period within 4-digit product groups to be broad-based. The import price in the median group increases by a mere $0.1 \%$. The mean increase is $1.4 \%$, but this somewhat elevated figure is driven by price increases in small product groups. When weighted by their contribution to imports, the mean price increase during the crisis drops to $0.4 \%$, as already reported in Figure 7.

We also perform several exercises to directly relate import price adjustments to expenditure switching across the 4-digit product groups during the crisis. First, a simple correlation between expenditure switching growth rates, as reported in Figure 6, and import price adjustments, as reported in Figure 8, is -0.12 , and becomes even weaker, when small product groups are dropped from the sample. Second, we calculate contributions to expenditure switching separately for product groups with increasing and decreasing import prices. This is an instructive exercise, because regardless of elasticity assumptions, conventional macro models predict that expenditure switching should take place only in product groups where import prices increased. We find, instead, that $45 \%$ of the aggregate expenditure switching during the crisis took place in product groups with falling, not increasing, import prices. Overall, the data shows no sizable systematic adjustment in import prices and no systematic relationship between import price adjustments and expenditure switching within 4-digit

\footnotetext{
${ }^{24}$ Given some policy actions taken by the government during the crisis, such as increase in taxes on alcoholic beverages, we have examined whether any given product group drove this change in relative price. We found that no single product group drove the movement in the aggregate relative price, including alcoholic beverages.

${ }^{25}$ The number of groups (265) included in Figure 8 is smaller than the number of groups (291) included in Figure 6, because for some 4-digit product groups with a small number of observations we can compute changes in expenditure shares but not the price adjustment. Excluded product groups account for $3.8 \%$ of total expenditures on F\&B.
} 
product groups during the crisis.

\subsection{Finding 3: Shifts in Within-Group Item Mix}

In the absence of a systematic relative price adjustment within sectors, this section explores alternative sources of expenditure switching. The section documents a large dispersion in item unit values within 4-digit product groups and a pervasive within-group substitution towards cheaper items during the crisis. This substitution is then linked to expenditure switching from more expensive imported items to cheaper domestic substitutes. In the subsequent section the proposed expenditure switching channel is estimated and quantified more formally.

\subsubsection{Unit Value Dispersion and Flight to Cheaper Substitutes}

There are large differences in item unit values within product groups. ${ }^{26}$ Figure 9 plots the distribution of interquartile ranges of unit values for each product group, where the interquartile range of a given product group is defined as the difference between the unit value of the goods at the $75^{\text {th }}$ and $25^{\text {th }}$ percentiles of the product group's distribution of unit values. We find that for the median product group, the unit value at the $75^{\text {th }}$ percentile is $53 \%$ larger than the $25^{\text {th }}$ percentile, while the mean difference is $67 \%$.

The observed dispersion in unit values is broad-based across data subsets. Table 5 summarizes the extent of the dispersion by focusing on four measures: the median and mean unit value differences between the $75^{\text {th }}$ and $25^{\text {th }}$ percentiles, the standard deviation of unit values within product groups, and the number of items sold in the median product group. Results are reported for all items as well as subsets of data broken down by an item's origin. Regardless of the examined subset, there are sizable differences in unit values at the $75^{\text {th }}$ and $25^{\text {th }}$ percentiles, ranging between $39 \%$ and $53 \%$ for the median product group. The dispersion is some $25 \%$ smaller for domestic items, when compared to foreign ones. ${ }^{27}$

The documented dispersion in unit values within narrow 4-digit product groups potentially offers an alternative margin for substitution: during the crisis and in the absence of any significant price adjustment, consumers might have switched to lower unit value

\footnotetext{
${ }^{26}$ Examination of unit value differences within 4-digit product groups requires restricting the data to comparable 'net' units (e.g., kilograms, liters) within each product group. This is implemented by (i) dropping product groups where 'pieces' are used as the measure of units and (ii) limiting each group to items measured in common units. Imposing these two restrictions decreases total expenditures in the dataset by correspondingly $7.6 \%$ and a further $2.1 \%$.

${ }^{27} \mathrm{~A}$ similar unit value dispersion is found if the data are split by (a) store type, and (b) product groups with higher/lower unit values of imported relative to domestic items.
} 
items. To examine this possibility, we construct a Laspeyres-type expenditure share index for group $g$ between $t$ and $t+1$ :

$$
\begin{aligned}
\Delta W_{g t}= & \sum_{i}\left(\ln \varphi_{i g t+1}-\ln \varphi_{i g t}\right)\left(\ln p_{i g t}-\ln \bar{p}_{g t}\right) \\
= & \underbrace{\sum_{i}\left(\ln \phi_{i g t+1}-\ln \phi_{i g t}\right)\left(\ln p_{i g t}-\ln \bar{p}_{g t}\right)}_{\text {Quantity }}+\underbrace{\sum_{i}\left(\ln p_{i g t+1}-\ln p_{i g t}\right)\left(\ln p_{i g t}-\ln \bar{p}_{g t}\right)}_{\text {Price }} \\
& +\underbrace{\ln F_{g} \sum_{i}\left(\ln p_{i g t}-\ln \bar{p}_{g t}\right)}_{\approx 0},
\end{aligned}
$$

which sums changes in item expenditure shares, defined as $\varphi_{i g t} \equiv p_{i g t} q_{i g t} / \sum_{i} p_{i g t} q_{i g t}$, multiplied by each item's unit value, relative to the group's average base year unit value, defined as $\bar{p}_{g t} \equiv \sum_{i} p_{i g t} q_{i g t} / \sum_{i} q_{i g t}{ }^{28}$ The second line further decomposes the index into contributions from changes in items' prices ("Price") and quantity shares ("Quantity"), defined as $\phi_{i g t} \equiv q_{i g t} / \sum_{i} q_{i g t}$, and a residual term that is approximately zero by definition. ${ }^{29}$

This index can isolate systematic shifts in expenditure shares between high and low unit value items. When expenditures are shifting towards less expensive items, the index takes a negative value and vice versa when expenditures shift systematically towards more expensive items. The quantity and price components allow us to separate between the two key sources of shifts in expenditures. The quantity component of the index in (6) takes on negative values when quantity shares shift toward less expensive items, while the price component takes on positive values when the relative price of lower unit value items is decreasing.

We compute the quantity and price components of $\Delta W_{g t}$ for each 4-digit product group $g$ and each $t$ using quarterly data. Indexes for individual 4-digit product groups are then aggregated into an overall index using each group's weight in total F\&B expenditures, and the resulting index is re-expressed in y-o-y changes to avoid seasonality. Similar results are obtained if unweighed mean or median changes in the indexes are considered instead.

The resulting aggregated quantity and price components, reported in panel (a) of Figure 10, show that the consumed quantities of high/low unit value items within product groups varied systematically with the boom-bust-recovery cycle. In particular, during the crisis the quantity component (solid line) turned negative, with a trough for the shift towards less expensive items in mid-2009. Panels (b)-(d) show that a similar shift in consumed quantities towards less expensive items was present within imported items, within domestic

\footnotetext{
${ }^{28}$ We are indebted to a referee for suggesting this index.

${ }^{29}$ Since $F_{g} \equiv\left(\sum_{i} q_{i g t+1} / \sum_{i} q_{i g t}\right)\left(\sum_{i} p_{i g t} q_{i g t} / \sum_{i} p_{i g t+1} q_{i g t+1}\right)$ is a constant term.
} 
items as well as within store products, for which we are not able to identify origin. ${ }^{30}$ At the same time, we find no systematic shifts in the relative price of low/high unit value items (dashed line) over the boom-bust-recovery cycle. In particular, there is no evidence that during the crisis the shift in quantities towards lower unit value items was facilitated by a decrease in the relative price of lower unit value items, as would be captured by positive values of the price component in (6).

\subsubsection{Shifts in Item Mix and Expenditure Switching}

The key question for this paper is whether the shift in the consumed item mix towards lower unit values during the crisis induced expenditure switching - a reallocation of expenditures from expensive foreign items to less expensive domestic ones. This section argues that this was indeed the case. We show that imported goods tend to be more expensive, which in combination with the documented shift towards lower unit values during the crisis induced the expenditure switching.

To compare price levels of domestic and imported goods, we compute for each item the sample median relative unit value within its 4-digit product group, $\bar{p}_{i g}$, based on available observations for $p_{i g t} / \bar{p}_{g t}$, and then compare the average unit value of imported and domestic goods in each product group, $\bar{p}_{g}^{F} / \bar{p}_{g}^{D}$. Figure 11 plots the distribution of the resulting foreign/domestic unit value differences across product groups. Imported items are on average $28 \%$ more expensive than their domestic counterparts in the median product group. The mean difference is $32 \%$. These differences are persistent over time, with the mean difference varying between $26 \%$ and $37 \%$.

Figure 11 also reveals sizable heterogeneity in the relative unit value of foreign to domestic items across product groups. Although imported goods are more expensive on average, the reverse is true for a fraction of product groups accounting for $19 \%$ of total expenditures in the dataset. This heterogeneity in average foreign/domestic unit values across product groups can be explored to link shifts in the consumed item mix with expenditure switching. In particular, we begin by computing the quantity component of the index in (6) separately for two data subsets: one containing product groups where imported items are on average more expensive, and the other containing product groups where domestic items are on average more expensive. Figure 12 shows that quantities consumed shifted towards lower cost unit value items in both data subsets. ${ }^{31}$ For the subset of product groups where imports

\footnotetext{
${ }^{30}$ We also find the same shift in item mix present when the data are split by the store type.

${ }^{31}$ The price change components (not shown) are close to zero.
} 
are more expensive (the solid line), which represents $81 \%$ of total expenditures, this finding suggests that consumers re-allocated expenditures from more expensive imports to less expensive domestic goods.

However, the item-level index in (6) leaves open the possibility that the switching within product groups is taking place within domestic and within imported items rather than across the two item types. To address this concern, we impose within group-source homogeneity and aggregate domestic and imported items in each product group into two composite goods - one containing all domestic items and the other containing all imported items - and then re-compute the index. Formally, the quantities and prices of the two composite goods are computed as $q_{g t}^{j}=\sum_{i \in I_{g t}^{j}} q_{i g t}$ and $p_{g t}^{j}=\sum_{i \in I_{g t}^{j}} p_{i g t} q_{i g t} / \sum_{i \in I_{g t}^{j}} q_{i g t}$, where $j=\{D, F\}$ denotes the subsets of domestic and imported items in product group $g$. An index analogous to (6) is then constructed as

$$
\Delta W_{g t}^{F / D}=\sum_{j}\left(\ln \varphi_{g t+1}^{j}-\ln \varphi_{g t}^{j}\right)\left(\ln p_{g t}^{j}-\ln \bar{p}_{g t}\right),
$$

where $\varphi_{g t}^{j} \equiv p_{g t}^{j} q_{g t}^{j} / \sum_{i \in I_{g t}^{j}} p_{g t}^{j} q_{g t}^{j} \cdot{ }^{32}$

The index in (7) eliminates all sources of switching between items, except for switching that takes place between the two composite (domestic and imported) goods. Consequently, when applied to product groups where the composite imported good is relatively more expensive than its domestic counterpart, a negative index value implies expenditure switching towards the composite domestic good. ${ }^{33}$

Figure 13 plots two indexes based on (7), where the solid line denotes the index for product groups with a more expensive foreign composite good, and the dashed line denotes the index for product groups with a more expensive domestic composite good. As can be seen, these composite indexes follow the same pattern as the item-level indexes in Figure 10 and Figure 12, exhibiting negative values during the crisis. Thus, even when the switching is limited to shifts across imported/domestic goods, consumers substituted towards less expensive goods during the crisis. For product groups where foreign goods are more expensive, Figure 13 implies expenditure switching. For the product groups where domestic goods are more expensive the shift in expenditures towards lower unit value imported goods is somewhat less pronounced. This more subdued 'reverse' expenditure switching can in

\footnotetext{
${ }^{32}$ We do not show the quantity and price components of this index separately, because Section 3.2 already documents the (lack of) relative price adjustment for imported goods. Results for a quantity share index are almost identical to the findings for the expenditure share index.

${ }^{33}$ To construct this index series, we restrict the dataset to 4-digit product groups that have at least one domestic and foreign items in each period, and eliminate extreme growth rates in the constructed expenditure shares for the two composite goods, which can generate noise in the series given the level of aggregation.
} 
part be explained by the reduced scope for savings from switching expenditures in product groups where domestic goods are on average more expensive. In such product groups the domestic composite good is $20.6 \%$ more expensive (in the median group), while for product groups where imported goods are more expensive the median price differential is $49.6 \%$.

To map the findings based on the two types of product groups in Figure 13 into the traditional measure of expenditure switching, as depicted in Figure 5, we compute total expenditure switching for each type of groups $\left(\bar{p}_{g}^{F}>\bar{p}_{g}^{D}\right.$ and $\left.\bar{p}_{g}^{D}>\bar{p}_{g}^{F}\right)$, and find that the switching from higher unit value imported items to lower unit value domestic items dominates. During the crisis period, aggregate expenditure switching is generated entirely by groups in which imported goods are on average more expensive, accounting for $105 \%$ of aggregate expenditure switching in Figure 5. Meanwhile, the import share actually increased in product groups where domestic goods are more expensive, amounting to a $-5 \%$ contribution to the aggregate expenditure switching from foreign to domestic goods.

Our finding that there is switching towards items with lower unit values during crises is consistent with earlier findings by Burstein et al. (2005). To the best of our knowledge, however, there is no evidence on differences in the unit values of domestic and imported goods given the lack of available data, nor on how consumers switch from higher unit value foreign goods to lower unit value domestic goods. Work examining scanner-level data in the U.S. has noted that consumers search for cheaper goods by switching stores during recessions (Coibion et al., 2015), as well as differences in consumption across cities and household income levels (Handbury, 2013), but no one has examined the international dimension yet.

In sum, the empirical findings presented in this section provide evidence that expenditure switching in Latvia was primarily driven by substitution between domestic and foreign goods within detailed product groups. However, this switching was not accompanied by a corresponding relative price change. Rather, we provide evidence that consumers switched between cheap and expensive goods as income fluctuated, and in particular that they substituted from expensive foreign goods to cheaper domestic ones during the crisis. ${ }^{34}$ One remaining issue with the findings reported in this section is that the constructed expenditure and quantity share indexes do not allow for the interpretation of the economic magnitudes of the expenditure switching that our proposed channel can account for. This issue is

\footnotetext{
${ }^{34}$ We have also examined an alternative approach at capturing shifts in item mix within product groups, based on a decomposition of the change in product group's average unit value into contributions from underlying changes in item prices and quantities (see Boorstein and Feenstra, 1987). Finding from this methodology are similar to results in Section 3.3 and are available from the authors upon request.
} 
addressed in the following section.

\section{Demand Model Estimation}

To formally quantify the importance of relative prices and income on expenditure switching, we model a consumer's expenditure allocation for $\mathrm{F} \& \mathrm{~B}$ to provide structure for an estimation strategy, which exploits the dataset at the item level. We follow the literature that uses scanner-level data and model the expenditure allocation as a two-stage decision, where a consumer first allocates expenditures across grocery product groups (tea, coffee, cacao, etc), and then allocates expenditures between UPC items within product groups. ${ }^{35}$

Given the documented heterogeneity in unit values within product groups (see Finding 3 ), we also build in a channel through which consumers may substitute between low and high priced goods when faced with an income shock, such as the one experienced by Latvia during the crisis. In particular, we borrow from the setup of Hallak (2006)'s model, which allows goods to vary by quality, and for the consumer's intensity of demand for quality to depend on her income level. These modifications of the standard CES demand system introduce a non-homotheticity at the bottom layer of the utility function. ${ }^{36}$ The higher the income the more the consumer values the higher quality items. Though we are not modeling quality formally here, since other factors may drive the difference in prices across domestic and foreign goods (e.g., transport costs), this strategy captures an important potential channel that we wish to test; i.e., that consumers substituted to cheaper goods (within a product group) during the crisis, irrespective of relative price changes.

Appendix C provides the setup and solution to the consumer's allocation problem, and derivation of the within-group expenditure share, which is a function of relative prices and a quality parameter. The solution does not specify a function for how income affects a consumer's allocation of expenditures, but to provide an estimation strategy, we follow Hallak (2006) and assume that the consumer's intensity for demand of an item's quality in a given group is a linear function of aggregate expenditures. Given this assumption and the model solution, we can write the log-difference of item's $i$ within-group $g$ expenditure share

\footnotetext{
${ }^{35}$ See, Broda and Weinstein (2010) or Handbury (2013) for recent contributions using nested utilities and scanner-level data. Blackorby et al. (1978) is an early contribution that uses nested utility, and which also allows for non-homothetic preferences.

${ }^{36}$ Hallak (2006) takes the supply of quality and income as exogenous in a partial equilibrium setting, like ours. See Feenstra and Romalis (2014) for a general equilibrium model, where quality is an endogenous outcome. Furthermore, Choi et al. (2009) and Fajgelbaum et al. (2011) study how countries' income distributions affects trade and quality in a more general setting.
} 
at time $t, \varphi_{i g t}$, as

$$
\Delta \ln \varphi_{i g t}=\Delta \ln N_{g t}+\left(1-\sigma_{g}\right) \Delta \ln \left(\frac{p_{i g t}}{P_{g t}}\right)+\left(\sigma_{g}-1\right) \mu_{g} \ln \theta_{i g} \Delta \ln C_{t},
$$

where $N_{g t}$ is the total number of items in product group $g ; \sigma_{g}$ is the elasticity of substitution between items in group $g$; $p_{i g t}$ is an item $i$ 's price level; $P_{g t}$ is group $g$ 's price index; $\mu_{g}$ is a group $g$ specific coefficient that captures the importance of aggregate expenditures on the intensity of demand of an item's quality, denoted by $\theta_{i g}$; and $C_{t}$ is aggregate expenditures.

\subsection{Estimation Strategy}

We operationalize the estimation of (8) using the following baseline linear regression:

$$
\Delta \ln \varphi_{i g t}=\alpha_{g t}+\beta_{1 g} \Delta \ln \left(\frac{p_{i g t}}{P_{g t}}\right)+\beta_{2 g} \ln \bar{p}_{i g} \Delta \ln C_{t}+\varepsilon_{i g t},
$$

where $\alpha_{g t}$ is a 4-digit product group $\times$ time fixed effect, which absorbs all explanatory variables that only vary in the $g t$ dimension; $\beta_{1 g} \equiv 1-\sigma_{g} ; \beta_{2 g} \equiv \mu_{g}\left(\sigma_{g}-1\right) ; \bar{p}_{i g}$ is a proxy for the quality parameter $\theta_{i g}$, and is calculated as the sample median of each item's relative unit value within a product group, $p_{i g t} / \bar{p}_{g t}$, where the group's average unit value $\bar{p}_{g t}$ is defined below (6), and $\varepsilon_{i g t}$ is as random disturbance term. As in the model, we interact the "quality" term $\ln \bar{p}_{i g}$ with the growth rate of income, $\Delta \ln C_{t} .{ }^{37}$ We use quarterly real per-capita household consumption for $C_{t}$, which we take from the International Financial Statistics (IMF).

We estimate (9) using the same data sample as described in Section 3, though we drop four 4-digit product groups that do not contain enough data to identify the coefficients of interest. The final regression sample comprises of 372,484 store item $\times$ time observations, and 387 product groups. ${ }^{38}$ We estimate two versions of the baseline regression (9). The first model, which we call the 'CES' model, restricts all $\beta_{2 g}$ to 0 . Therefore, only changes in relative prices will affect an item's share. The second model, which we call the ' $\mathrm{NH}$ ' (non-homothetic) model, runs (9) unrestricted.

The estimating equation (9) is based on a partial equilibrium demand model, which treats several variables as given, and ignores potential shocks that may impact both the quantity and the price of goods, thus inducing a correlation between $\varepsilon_{i g t}$ and price changes.

\footnotetext{
${ }^{37}$ We use the terminology of "income" rather than "expenditure" in what follows for ease of exposition.

${ }^{38} \mathrm{We}$ also experimented with restricting the sample so that each product groups contains a minimum of 500 observations over the whole sample period, which cuts the sample to 143 product groups. Furthermore, we also run regressions dropping the alcoholic beverage product groups. Results were robust to these restrictions, and are available upon request.
} 
Furthermore, the aggregate price indexes are model-based, and therefore a function of some of the parameters we wish to estimate. To address these issues, our estimation strategy follows a multi-pronged approach, which addresses: (1) biases due to measurement error induced by deviations from model-based price indexes; (2) supply shocks that may have impacted the relative supply of domestic and imported goods; (3) price discrimination by firms at the item level; and (4) omitted variable bias. Our strategy relies on different fixed effect configurations, as well two instrumental variables estimation approaches. All details are described in Appendix D.

\subsection{Estimation Results}

Table 6 presents baseline results for the estimated heterogeneous coefficient regression model (9). The estimators presented are weighted means of the estimated coefficients, where the weights are based on a product group's average expenditure share over the sample. ${ }^{39}$ Column (1) presents results for the CES model, where we only consider relative price changes and ignore potential income effects. The estimated relative price coefficient is -2.938 , and is significant at the $1 \%$ level. This coefficient implies a price elasticity, $\sigma$, equal to $3.938 .{ }^{40}$ Column (2) next presents the baseline results for the NH model. The estimated $\beta_{1}$ coefficient remains virtually unchanged and the estimated $\beta_{2}$ coefficient is positive and significant, with a value of 1.701 , which implies a value of $\mu$ equal to 0.579 .

Appendix D expands the estimation strategy along several lines, including more restrictive sets of fixed effects, non-linear effects, instrumental variables, and numerous sample splits and other robustness checks (see Table A1-Table A4). The core results of this section are robust to all these modifications.

\subsection{Predicted Aggregate Expenditure Switching}

This section explores the quantitative importance of the estimated price and income effects in driving aggregate expenditure switching. Using the item-level data and the baseline estimated heterogeneous parameters for the CES and NH models, as summarized in Table 6, we predict each item's share in a given product group, and aggregate all predicted shares of imported goods in order to calculate the predicted import share in total F\&B expenditures,

\footnotetext{
${ }^{39}$ We choose to present weighted-means rather than simple means, since the predicted aggregate expenditure switching in Section 4.3 is also based on product-group weights and heterogeneous coefficients. Results for the unweighted means are available upon request.

${ }^{40}$ This elasticity is the same order of magnitude compared to previous estimates using retail level prices, such as for the coffee market (Nakamura and Zeron, 2010), or using scanner data across many goods (Handbury, 2013).
} 
and the corresponding expenditure switching for all sample periods, which we compare to the data. We focus on within-group expenditure switching. Furthermore, we only look at the share changes as predicted by either (i) changes in relative prices, or (ii) the income effect, and thus do not include the group $\times$ time fixed effects in calculating the predicted growth rates of the items' shares. Appendix E outlines all the details of the aggregation exercise.

Figure 14 plots the actual and predicted within-group y-o-y expenditure switching. The first fact to note is that the within-group expenditure switching observed in the data (the solid line) has very similar dynamics compared to the within-group component plotted in Figure 5, which was calculated using a slightly larger data sample (including items that did not exist for two consecutive periods). Next, comparing the two models' predicted expenditure switching to that of the data in Figure 14, the predicted expenditure switching for the CES model (dash-dot line) does a very poor job in tracking the actual withingroup expenditure switching observed in the data, particularly during the crisis period when income dropped substantially. However, the non-homothetic model's predicted values (dash line) appear to track the data better throughout the sample, and match the switching during the pre-crisis boom period, as well as the switching during the crisis. In terms of quantities, year-on-year within component of expenditure switching at its peak in Q3:09 shows the import share falling by 0.022 . For the same period, the CES model predicts an increase in the import share by 0.002 , while the non-homothetic model predicts a fall in the import share by 0.015 . Therefore, the CES model does not explain any expenditure switching between domestic and imported goods at the aggregate level (and in fact goes in the wrong direction), while the non-homothetic model is able to explain around twothirds of what is observed in the data during the crisis. Figure 15 decomposes predicted expenditure switching of the non-homothetic model into separate price (dash-dot line) and income (dash line) effects. We calculate these by either shutting down the price effect $\left(\beta_{1 g} \mathrm{~s}\right.$ $=0)$, or the income effect $\left(\beta_{2 g} \mathrm{~s}=0\right)$, and then predict the log change in item's shares, and aggregate up. It is clear that the income effect is responsible for almost all of the predicted expenditure switching.

\section{Conclusion}

This paper measures what drove expenditure switching in Latvia during a sudden stop episode in 2008-09, using a supermarket scanner-level dataset. Contrary to conventional theory, relative price changes did not drive expenditure switching. Instead, this paper's 
findings show that the fall in income during the crisis led consumers to substitute from foreign to domestic goods, since foreign goods were on average more expensive than domestic ones. This non-homothetic channel is estimated using a simple model that allows for quality differences across goods, where the consumer's intensity of demand for quality varies with income.

The analysis in this paper focuses on substitution between domestic and imports goods in a particular sector of the economy and for a country that maintained a peg during the crisis. Future work should investigate how relevant this non-homothetic channel is in a more general setting, which incorporates exports and other sectors of the economy, as well as study how results vary across exchange rate regimes. Furthermore, this paper remains silent on several issues that are left for future work using the scanner-level dataset, possibly combined with micro supply-side data. There is need for a better understanding of what drove changes (or lack there of) in the relative price of domestic and foreign goods following Latvia's internal devaluation. Furthermore, what store-level maximization behavior would rationalize the results found in this paper given the macroeconomic situation faced by Latvia? Answering such questions, as well as gaining further insight into the price dynamics is important to better understand the implications of policy prescriptions such as "internal devaluations."

\section{References}

Ahn, JaeBin, Mary Amiti, and David E. Weinstein, "Trade Finance and the Great Trade Collapse," American Economic Review: Papers $\&$ Proceedings, May 2011, 101 (3), 298302.

Alchian, Armen A. and William R. Allen, University Economics, Belmont, CA: Wadsworth Publishing Company, 1964.

Alessandria, George, Joseph P. Kaboski, and Virgiliu Midrigan, "Inventories, Lumpy Trade, and Large Devaluations," American Economic Review, December 2010, 100 (5), 23042339 .

Bems, Rudolfs, Robert C. Johnson, and Kei-Mu Yi, "The Great Trade Collapse," Annual Review of Economics, 2013, 5 (1).

Berger, David, Jon Faust, John H. Rogers, and Kai Steverson, "Border Prices and Retail Prices," May 2009. Board of Governors of the FRB, International Finance Discussion Paper No. 972.

Berka, Martin and Michael B. Devereux, "What Determines European Real Exchange Rates?," 2011. Mimeo, Victoria University of Wellington and UBC.

_ , _ , and Charles Engel, "Real Exchange Rate Adjustment in and out of the Eurozone," American Economic Review: Papers $\mathscr{G}$ Proceedings, May 2012, 102 (3), 179-185. 
Berthou, Antoine and Charlotte Emlinger, "Crises and the Collapse of World Trade: the Shift to Lower Quality," March 2010. CEPII Working Paper 2010-07.

Blackorby, Charles, Richard Boyce, and R. Robert Russell, "Estimation of Demand Systems Generated by the Gorman Polar Form; A Generalization of the S-Branch Utility Tree," Econometrica, March 1978, 46 (2), 345-363.

Blanchard, Olivier, Mark Griffiths, and Bertrand Gruss, "Boom, Bust, Recovery Forensics of the Latvia Crisis," Brookings Papers on Economic Activity, 2013, Fall, 325-371.

Boorstein, Randi and Robert C. Feenstra, "Quality Upgrading and its Welfare Cost in U.S. Steel Imports, 1969-74," 1987. NBER Working Paper No. 2452.

Broda, Christian and David E. Weinstein, "Product Creation and Destruction: Evidence and Price Implication," American Economic Review, June 2010, 100 (3), 691-723.

Burstein, Ariel and Gita Gopinath, "International Prices and Exchange Rates," in H. Helpman, K. Rogoff, and G. Gopinath, eds., Handbook of International Economics, Vol. 4, Amsterdam: Elsevier B.V., 2014, chapter 7, pp. 391-451.

_ , Martin Eichenbaum, and Sergio Rebelo, "Devaluations and the Real Exchange Rate," Journal of Political Economy, August 2005, 113 (4), 742-784.

_, , , and _ , "Modeling Exchange Rate Passthrough After Large Devaluations," Journal of Monetary Economics, March 2007, 54 (2), 346-368.

Campa, José Manuel and Linda S. Goldberg, "Distribution Margins, Imported Inputs, and the Sensitivity of the CPI to Exchange Rates," March 2006. NBER Working Paper No. 12121.

Cavallo, Alberto, Brent Neiman, and Roberto Rigobon, "Currency Unions, Product Introductions, and the Real Exchange Rate," Quarterly Journal of Economics, May 2014, 129 (2), 529-595.

Chen, Natalie and Luciana Juvenal, "Quality and the Great Trade Collapse," 2015. Mimeo, University of Warwick and IMF.

Choi, Yo Chul, David Hummels, and Chong Xiang, "Explaining Import Quality: The Role of Income Distribution," Journal of International Economics, April 2009, 77 (2), 265-275.

Coibion, Olivier, Yuriy Gorodnichenko, and Gee Hee Hong, "The Cyclicality of Sales, Regular and Effective Prices: Business Cycle and Policy Implications," American Economic Review, March 2015, 105 (3), 993-1029.

Corsetti, Giancarlo, Philippe Martin, and Paolo Pesenti, "Varieties and the Transfer Problem," Journal of International Economics, January 2013, 89 (1), 1-13.

Crucini, Mario J., Chris I. Telmer, and Marios Zachariadis, "Understanding European Real Exchange Rates," American Economic Review, June 2005, 95 (3), 724-738.

di Giovanni, Julian, Andrei A. Levchenko, and Isabelle Méjean, "Firms, Destinations, and Aggregate Fluctuations," Econometrica, July 2014, 82 (4), 1303-1340.

Diaz Alejandro, Carlos F., Exchange Rate Devaluation in a Semi-Industrialized Country: The Experience of Argentina 1955-1961, Cambridge, Mass.: The MIT Press, 1965.

Engel, Charles, "Expenditure Switching and Exchange Rate Policy," in Mark Gertler and Kenneth Rogoff, eds., NBER Macroeconomics Annual 2002, Vol. 17 The MIT Press Cambridge, Mass. 2003, pp. 231-272. 
- and Jian Wang, "International Trade in Durable Goods: Understanding Volatility, Cyclicality, and Elasticities," Journal of International Economics, 2011, 83 (1), 37-52.

Esposito, Piero and Claudio Vicarelli, "Explaining the Performance of Italian Exports during the Crisis: (Medium) Quality Matters," 2011. Mimeo, SSSA and ISTAT.

Faber, Benjamin, "Trade Liberalization, the Price of Quality, and Inequality: Evidence from Mexican Store Prices," 2014. Mimeo, U.C. Berkeley.

Fajgelbaum, Pablo and Amit Khandelwal, "Measuring the Unequal Gains From Trade," 2013. Mimeo, UCLA and Columbia University.

_- Gene M. Grossman, and Elhanan Helpman, "Income Distribution, Product Quality, and International Trade," Journal of Political Economy, August 2011, 119 (4), 721-765.

Farhi, Emmanuel, Gita Gopinath, and Oleg Itskhoki, "Fiscal Devaluations," Review of Economic Studies, 2013, 81 (2), 725-760.

Feenstra, Robert C., "New Product Varieties and the Measurement of International Prices," American Economic Review, March 1994, 84 (1), 157-177.

- and John Romalis, "International Prices and Endogenous Quality," Quarterly Journal of Economics, 2014, 129 (2), 477-527.

_, Philip Luck, Maurice Obstfeld, and Katheryn N. Russ, "In Search of the Armington Elasticity," April 2014. NBER Working Paper No. 20063.

Goldberg, Pinelopi Koujianou and Rebecca Hellerstein, "A Structural Approach to Explaining Incomplete Exchange-Rate Pass-Through and Pricing-to-Market," American Economic Review: Papers \& Proceedings, May 2008, 98 (2), 423-429.

Hallak, Juan Carlos, "Product Quality and the Direction of Trade," Journal of International Economics, January 2006, 68 (1), 238-265.

Handbury, Jessie, "Are Poor Cities Cheap for Everyone? Non-Homotheticity and the Cost of Living Across U.S. Cities," 2013. Mimeo, University of Pennsylvania.

Hausman, Jerry A., "Valuation of New Goods under Perfect and Imperfect Competition," in Timothy F. Bresnahan and Robert J. Gordon, eds., The Economics of New Goods, Chicago, IL: University of Chicago Press, January 1996, chapter 5, pp. 207-248.

Herrendorf, Berthold, Richard Rogerson, and Akos Valentinyi, "Growth and Structural Transformation," in Philippe Aghion and Steven N. Durlauf, eds., Handbook of Economic Growth, Vol. 2B, New York: Elsevier, 2014, chapter 6, pp. 855-941.

Hummels, David and Alexandre Skiba, "Shipping the Good Apples Out? An Empirical Confirmation of the Alchian-Allen Conjecture," Journal of Political Economy, December 2004, 112 (6), 1384-1402.

- and Peter J. Klenow, "The Variety and Quality of a Nation's Exports," American Economic Review, June 2005, 95 (3), 704-723.

Imbs, Jean and Isabelle Méjean, "Elasticity Optimism," February 2009. CEPR Discusion Paper 7177.

Ivancic, Lorraine, W. Erwin Diewert, and Kevin J. Fox, "Scanner Data, Time Aggregation and the Construction of Price Indexes," Journal of Econometrics, 2011, 161 (1), 24-35. 
Kang, Joong Shik and Jay C. Shambaugh, "The Evolution of Current Account Deficits in the Euro Area Periphery and the Baltics: Many Paths to the Same Endpoint," July 2013a. IMF Working Paper 13/169.

_ and _, "Progress Towards External Adjustment in the Euro Area Periphery and the Baltics," 2013b. Unpublished, IMF and GWU.

Kehoe, Timothy J. and Kim J. Ruhl, "Sudden Stops, Sectoral Reallocations, and the Real Exchange Rate," Journal of Development Economics, July 2009, 89 (2), 235-249.

Krugman, Paul, "Differences In Income Elasticities and Trends in Real Exchange Rates," European Economic Review, May 1989, 33 (5), 1031-1046.

Levchenko, Andrei A., Logan T. Lewis, and Linda L. Tesar, "The "Collapse in Quality" Hypothesis," American Economic Review: Papers and Proceedings, May 2011, 101 (3), 293-297.

Magee, Stephen P., "Currency Contracts, Pass-Through and Devaluation," Brookings Papers on Economic Activity, 1973, 1, 303-323.

Mendoza, Enrique G., "Real Exchange Rate Volatility and the Price of Nontradable Goods in Economies Prone to Sudden Stops," Economia, Fall 2005, pp. 103-145.

Nakamura, Emi and Dawit Zeron, "Accounting for Incomplete Pass-Through," Review of Economic Studies, 2010, 77 (3), 1192-1230.

Obstfeld, Maurice and Kenneth Rogoff, "The Unsustainable US Current Account Position Revisited," in Richard H. Clarida, ed., G7 Current Account Imbalances: Sustainability and Adjustment, University of Chicago Press Chicago, IL May 2007, pp. 339-376.

Parsley, David C. and Helen A. Popper, "Exchange rate pegs and Foreign Exchange Exposure in East and South East Asia," Journal of International Money and Finance, October 2006, 25 (6), 992-1009. 
Table 1. Aggregate Sales and Product Summary Statistics

\begin{tabular}{ccccc}
\hline \hline \multicolumn{5}{c}{ Panel A: All Products } \\
& $(1)$ & $(2)$ & $(3)$ & $(4)$ \\
& Total & Sales & Price & UPC-Store \\
Year & Sales & Growth & Change & Items \\
\hline & & & & \\
2006 & 235.7 & - & - & 42049 \\
2007 & 296.3 & 0.257 & 0.131 & 39423 \\
2008 & 336.7 & 0.137 & 0.079 & 38781 \\
2009 & 297.0 & -0.118 & -0.016 & 36794 \\
2010 & 302.0 & 0.017 & 0.024 & 36689 \\
\hline
\end{tabular}

Panel B: Domestic Products

\begin{tabular}{ccccc} 
& $(1)$ & $(2)$ & $(3)$ & $(4)$ \\
Tear & Total & Sales & Price \\
Growth & Change & $\begin{array}{c}\text { UPC-Store } \\
\text { Items }\end{array}$ \\
\hline & & & & \\
2006 & 135.7 & - & - & 12945 \\
2007 & 169.7 & 0.251 & 0.172 & 12308 \\
2008 & 197.4 & 0.163 & 0.078 & 11868 \\
2009 & 182.6 & -0.075 & -0.039 & 12220 \\
2010 & 184.0 & 0.008 & 0.039 & 12830 \\
\hline
\end{tabular}

Panel C: Foreign Products

\begin{tabular}{ccccc} 
& $(1)$ & $(2)$ & $(3)$ & $(4)$ \\
Tear & Sales & Price & UPC-Store \\
Sales & Growth & Change & Items \\
\hline & & & & \\
2006 & 100.0 & - & - & 29104 \\
2007 & 126.6 & 0.266 & 0.077 & 27115 \\
2008 & 139.4 & 0.101 & 0.080 & 26913 \\
2009 & 114.4 & -0.179 & 0.018 & 24574 \\
2010 & 118.0 & 0.032 & 0.001 & 23859 \\
\hline
\end{tabular}

Notes: This table presents summary statistics for all products aggregated across all types of stores at an annual level, where a year is defined from May-April (e.g., May06-April07) in order to maximize coverage. Column (1) presents total sales in millions of euros; Column (2) presents the annual growth rate of sales; Column (3) presents the annual inflation rate based on our constructed price indexes from store items; and Column (4) presents the total count of unique UPC-store items appearing in the sample in a given year. 


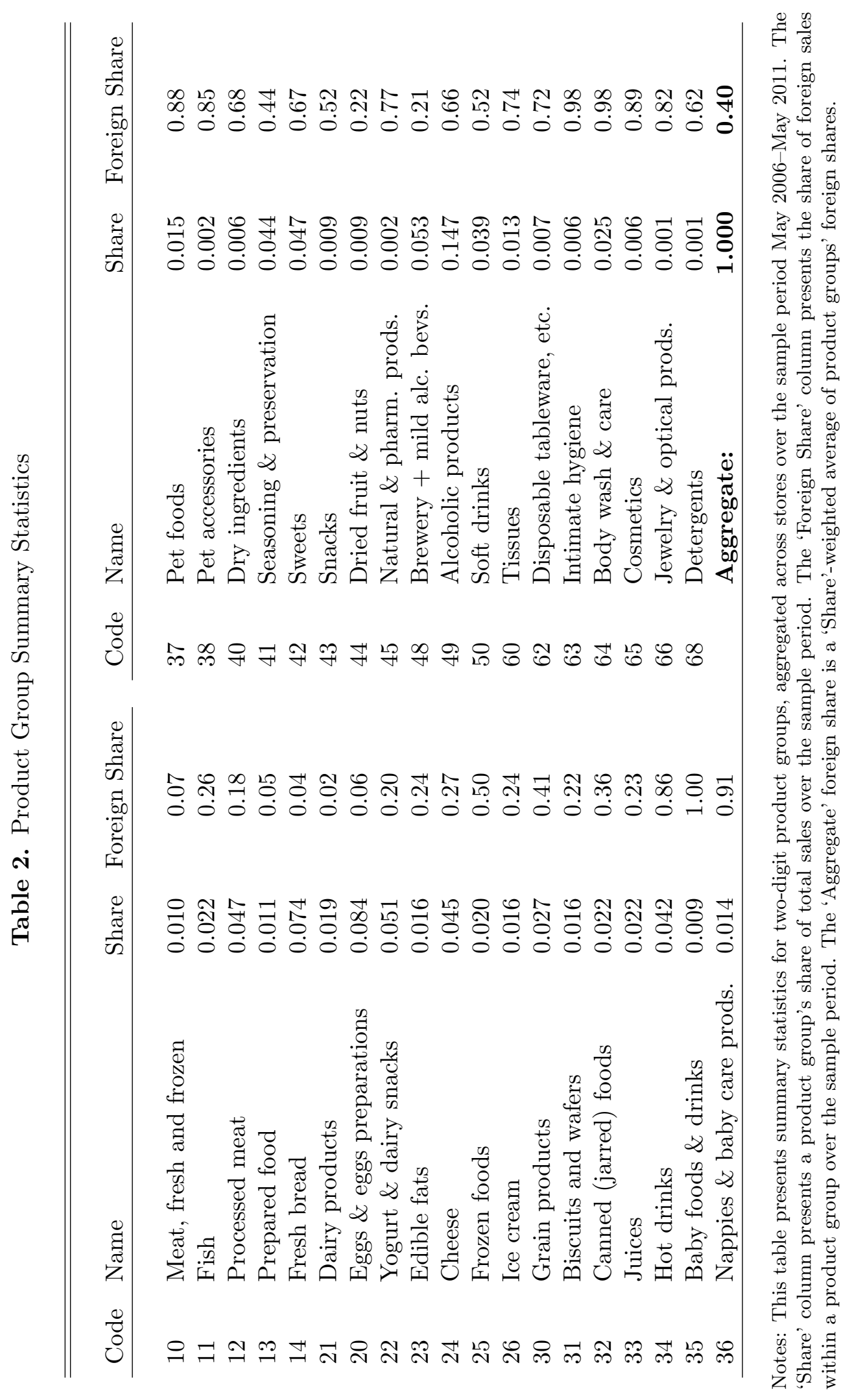


Table 3. Grocery Retail Market Share of Rimi in Latvia

\begin{tabular}{lccccc}
\hline \hline \multirow{2}{*}{ Year } & 2007 & 2008 & 2009 & 2010 & 2011 \\
\cline { 2 - 6 } Market share, \% & 20.0 & 21.7 & 22.5 & 22.4 & 21.5 \\
\hline
\end{tabular}

Source: IGD Retail Analysis.

Table 4. Latvian Imports: Durable and Non-Durable Goods

\begin{tabular}{ccccccc}
\hline \hline & \multicolumn{3}{c}{ Growth rate } & & \multicolumn{2}{c}{ Share } \\
& Total & Non-durable & Durable & & Non-durable & Durable \\
\cline { 2 - 3 } \cline { 6 - 7 } 2006 & 0.27 & 0.20 & 0.34 & & 0.44 & 0.56 \\
2007 & 0.19 & 0.15 & 0.22 & & 0.42 & 0.58 \\
2008 & -0.01 & 0.12 & -0.12 & & 0.48 & 0.52 \\
2009 & -0.44 & -0.28 & -0.62 & & 0.56 & 0.44 \\
2010 & 0.21 & 0.14 & 0.28 & & 0.53 & 0.47 \\
2011 & 0.30 & 0.25 & 0.36 & & 0.50 & 0.50 \\
2012 & 0.14 & 0.15 & 0.12 & & 0.51 & 0.49 \\
\hline
\end{tabular}

Notes: This table presents the breakdown of Latvian imports between durable and non-durable goods. Durability is defined following Engel and Wang (2011) and Levchenko et al. (2011). The first three columns present the growth rate of total, non-durable, and durable imports, respectively. The last two columns present the share of non-durable and durable goods in total imports. Source: Eurostat and authors' calculations.

Table 5. Unit Value Dispersion: All Items and Select Subsets

\begin{tabular}{|c|c|c|c|c|}
\hline & Median & Mean & St.Dev. & $\begin{array}{l}\text { No. of } \\
\text { Items }\end{array}$ \\
\hline All items & 0.53 & 0.67 & 0.58 & 33 \\
\hline \multicolumn{5}{|c|}{ By Item Origin } \\
\hline Foreign & 0.53 & 0.69 & 0.56 & 24 \\
\hline Domestic & 0.39 & 0.50 & 0.37 & 19 \\
\hline Store products & 0.47 & 0.62 & 0.43 & 18 \\
\hline
\end{tabular}

Notes: The means and medians are based on the distribution of the within product interquartile ranges of unit values across all 4-digit product groups over the entire sample. The interquartile range of a given product group is defined as the log ratio of the unit value of the items at the $75^{\text {th }}$ and $25^{\text {th }}$ percentiles of the product group, as reflect in the histogram in Figure 9. The 'St.Dev.' column measures the standard deviation of the unit values within a 4-digit product group over the sample, normalized by the mean unit value of the group over the sample. 'No. of Items' column reports the number of items sold in the median product group. 'Store products' refer to groups/items $\$ 1^{\text {that }}$ were dropped from the baseline dataset because of missing information about origin. 
Table 6. CES and Non-Homothetic Models' Heterogeneous Coefficient Regressions: Weighted-Mean Estimates

\begin{tabular}{lcc}
\hline \hline & & \\
& $(1)$ & $(2)$ \\
\cline { 2 - 3 }$\Delta \ln \left(p_{\text {igt }} / P_{g t}\right)$ & -2.938 & -2.949 \\
& $(0.028)$ & $(0.027)$ \\
$\ln \bar{p}_{i g} \times \Delta \ln C_{t}$ & & 1.701 \\
& & $(0.140)$ \\
\cline { 2 - 3 } Observations & 372,484 & 372,484 \\
Group $\times$ time F.E. & 7,344 & 7,344 \\
$R^{2}$ & 0.143 & 0.146 \\
\hline
\end{tabular}

Notes: This table presents weighted means of the coefficients of regression model (9). The weights are a product group's share of total expenditures over the sample period. Column (1) presents the price coefficients for the CES model, and column (2) presents the price and income coefficients for the non-homothetic model. These specifications are run with product group $\times$ time fixed effects. Standard errors clustered at the item level are in parentheses. 
Figure 1. Latvia's Balance of Payments Crisis of 2008-09

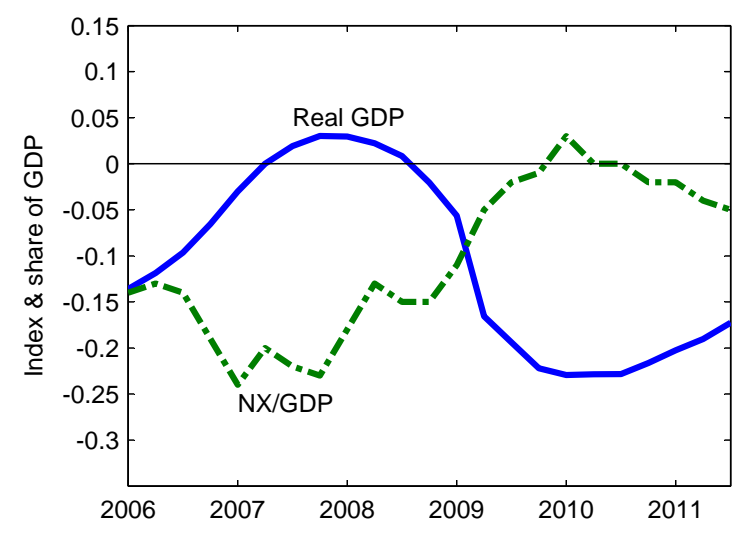

(a) GDP and net trade

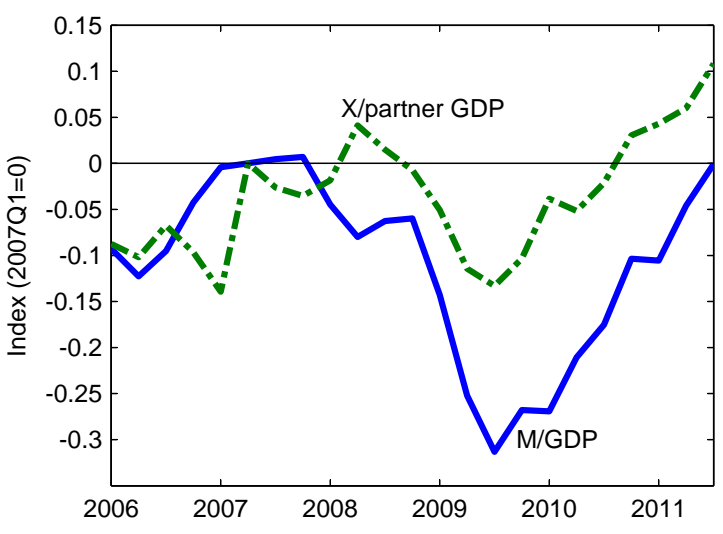

(b) Imports and exports

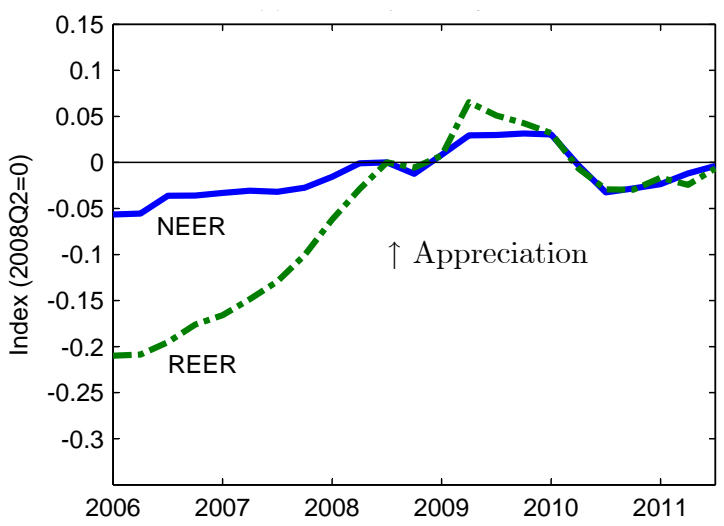

(c) Relative price adjustment

Notes: This figure plots the evolution of the key macro variables for Latvia around the 2008-09 crisis episode. 'NX/GDP' denotes net trade, as a share of GDP. In panel (a), 'Real GDP' is a seasonally adjusted $\log$ volume index, 'M/GDP' denotes imports of goods and services as a share of GDP, and 'X/partner GDP' denotes exports of goods and services as a share of trade partner GDP. All variables are normalized to zero in 2007Q1, and are based on data from the Central Statistical Bureau of Latvia, except partner GDP, which is from the IMF's International Financial Statistics (IFS). In panel (b), 'NEER' denotes the nominal effective exchange rate index, and 'REER' denotes the CPI-based real effective exchange rate index. Both indexes are normalized to zero in 2008Q2, and an increase in the indexes represents an appreciation. The NEER and REER data are from the IMF's IFS. 
Figure 2. Food and Beverages CPI and Aggregate Price Index from scanner-level data for Latvia

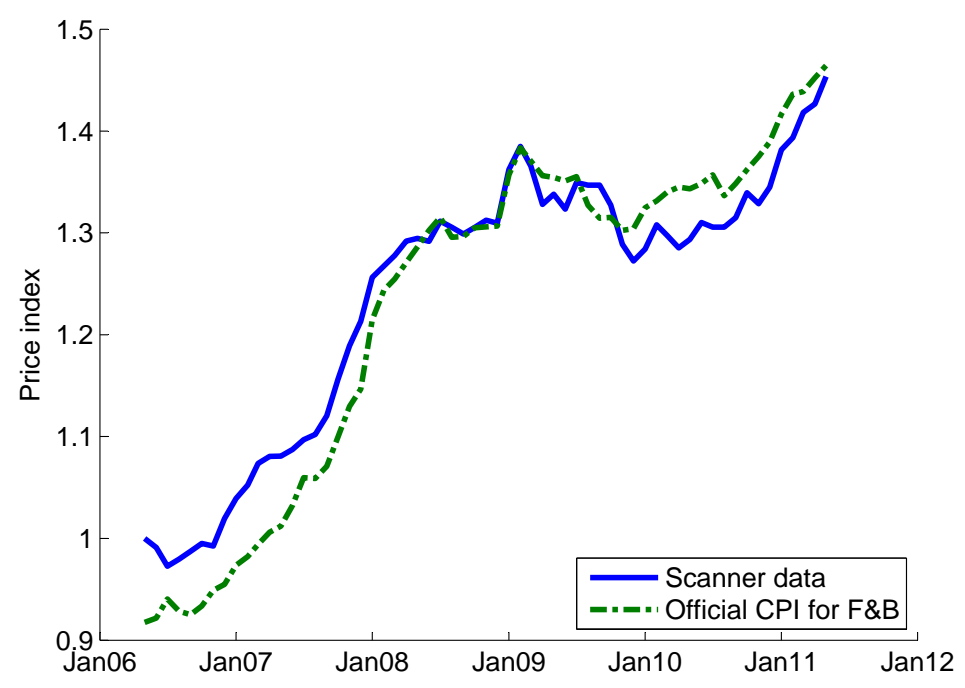

Notes: This figure plots the Latvian aggregate $\mathrm{CPI}$ for $\mathrm{F} \& \mathrm{~B}$, and an aggregate price index constructed using the scanner-level data. Sources: Central Statistical Bureau of Latvia and authors' calculations.

Figure 3. Food and Beverages Imports: Customs and scanner-level data

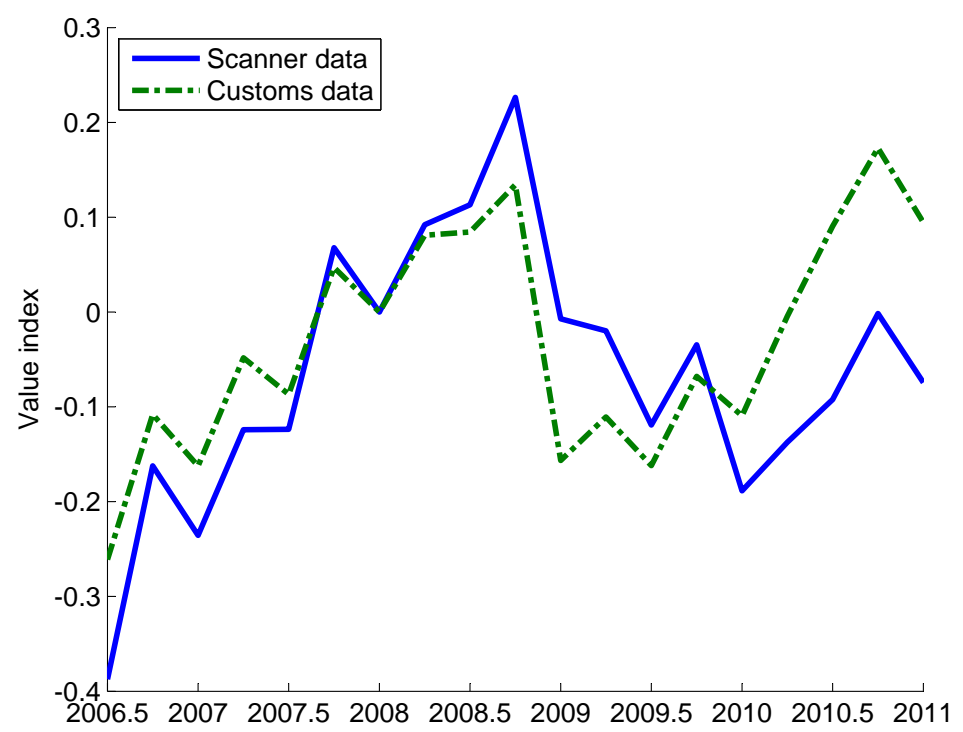

Notes: This figure plots value indexes of (i) aggregate imports of F\&B for final goods (based on UN BEC classification), and (ii) expenditures on foreign goods in the scanner-level data. Note that both series are scaled such that the 2008Q1 value is zero. Sources: Global Trade Information Services (http://www.gtis. com), UN Broad Economic Classification (http://unstats.un.org/unsd/cr/registry/regcst.asp? $\mathrm{Cl}=10$ ), and authors' calculations. 
Figure 4. Food and Beverages Fall During the Crisis

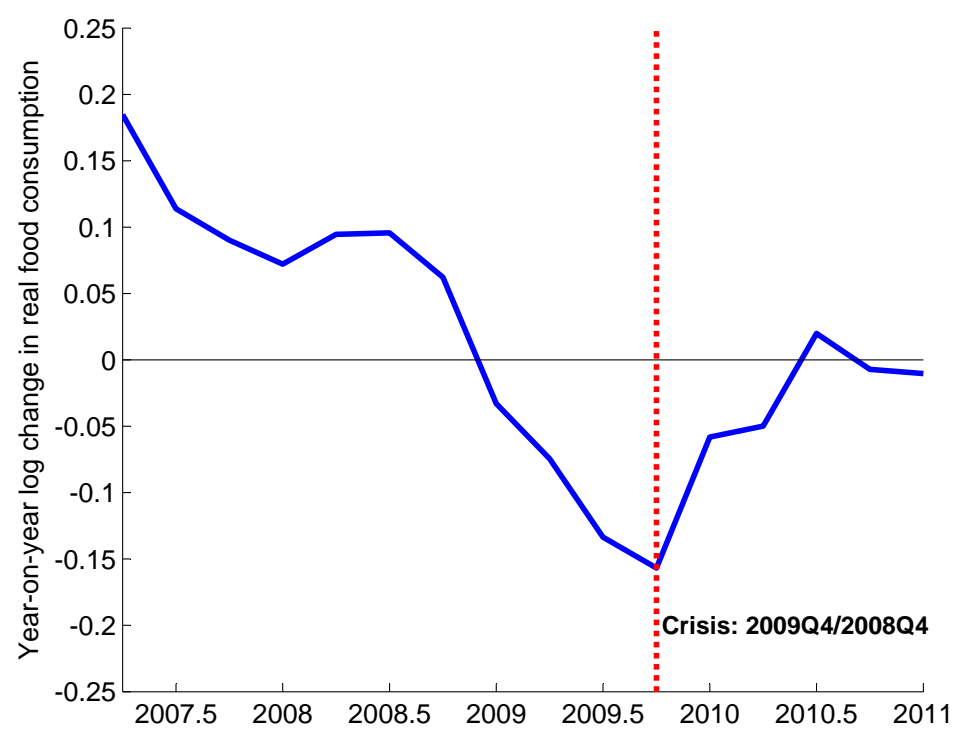

Notes: This figure plots the y-on-y log change of total real F\&B expenditures over the whole sample as measured using the scanner-level data.

Figure 5. Expenditure Switching: Total, Within and Across Product Groups

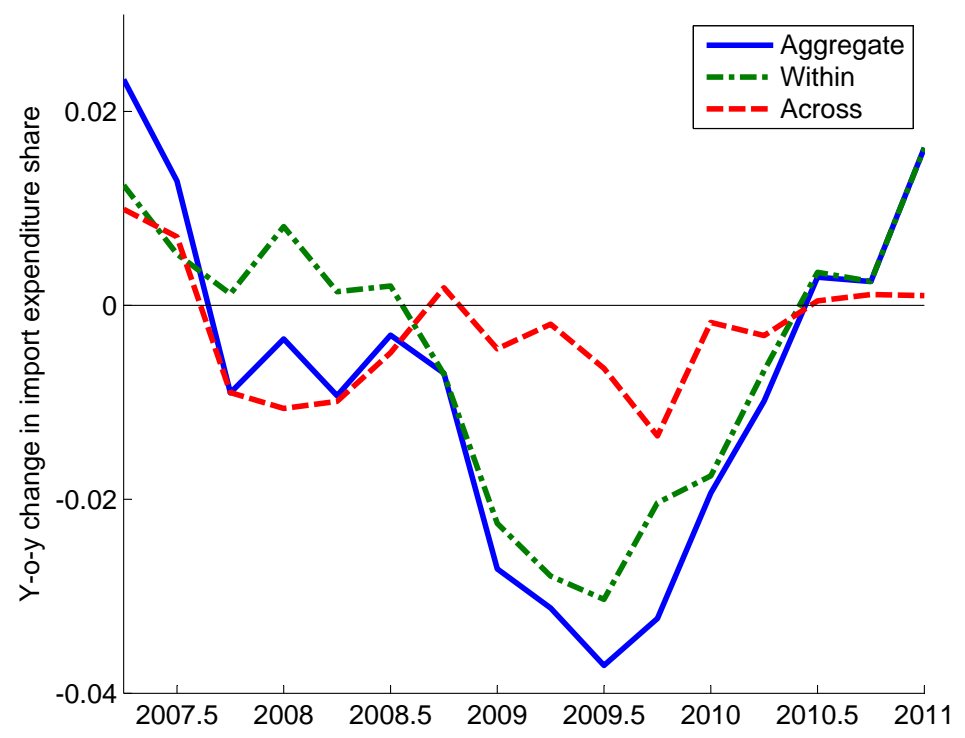

Notes: This figure plots the y-on-y change of the import share of total F\&B expenditures over the whole sample as measured using the scanner-level data. The total change in the import share is broken into the contribution due to switching expenditures across product groups and within product groups (i.e., by substituting between goods), calculated using (1). 
Figure 6. Distribution of Import Expenditure Share Growth Rates for 4-digit Product Groups over the Crisis Period

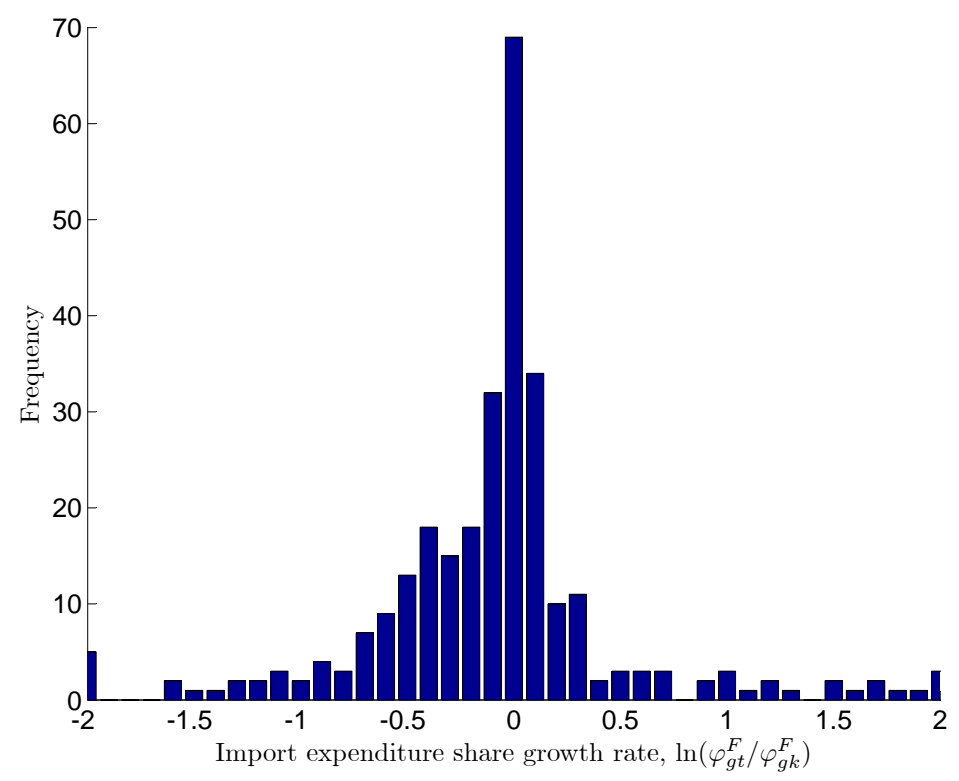

Notes: This figure summarizes the y-on-y expenditure switching growth rates at the 4-digit product group level over the crisis period, i.e., $t=2009$ Q4 and $k=2008$ Q4. There are 2914 -digit product groups with nonzero expenditures on domestic and imported goods. The growth rate in the median group is -0.04 and the mean is -0.15 .

Figure 7. Relative Price Change: Total, Within and Across Product Groups

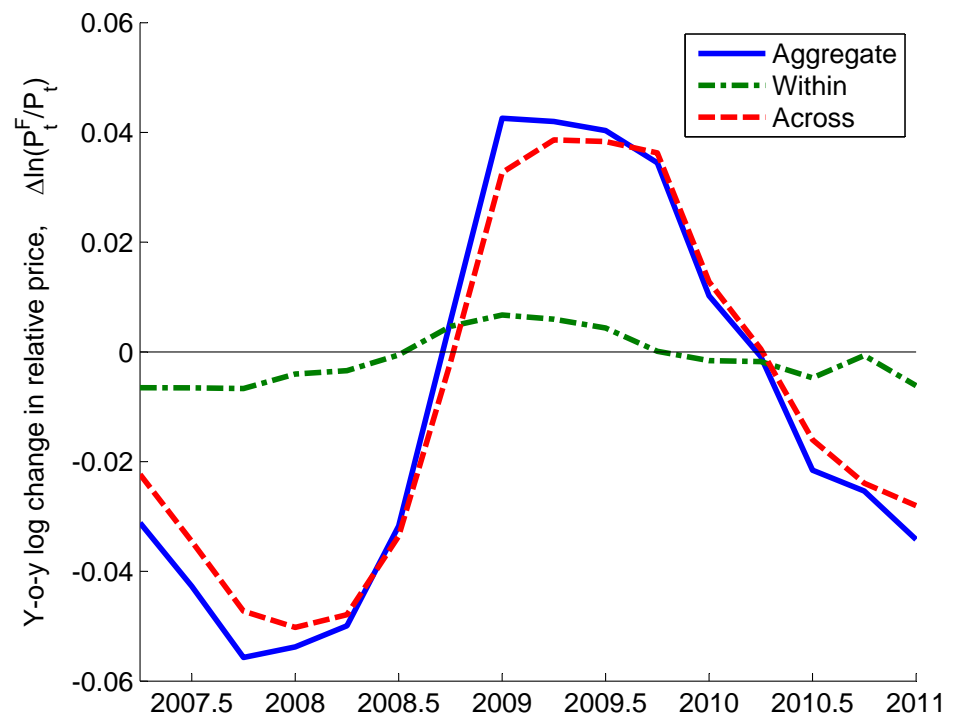

Notes: This figure plots the y-on-y change of the relative price of foreign goods for F\&B expenditures over the whole sample as measured using the scanner-level data. The total change in the relative price is broken into the contribution due to changes across product groups and within product groups (i.e., by substituting between goods), calculated using (5). 
Figure 8. Import Price Adjustments within 4-digit Product Groups during the Crisis Period

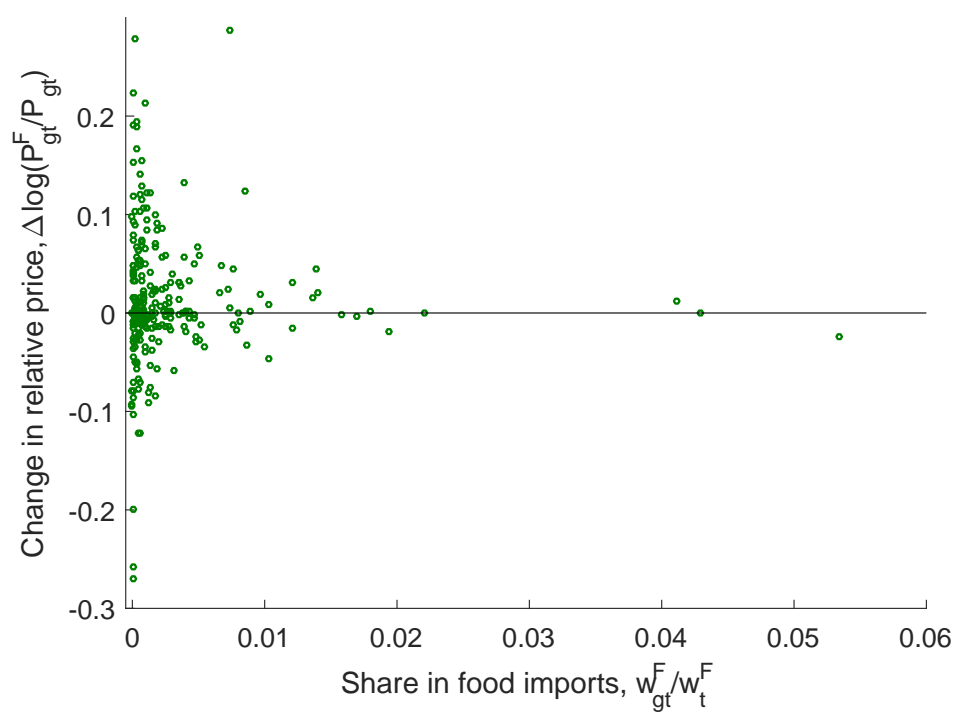

Notes: This figure reports import price adjustments for each of 265 4-digit product groups over the crisis period, i.e., Q4:09/Q4:08. Price adjustments are plotted against each product group's share in total imports prior to the crisis, i.e., Q4:08. The relative price of imports in the median group increases by 0.001 , while the mean increase is 0.013 .

Figure 9. Distribution of Within Product Group Interquartile Range Unit Values at the 4-Digit Product Code Level

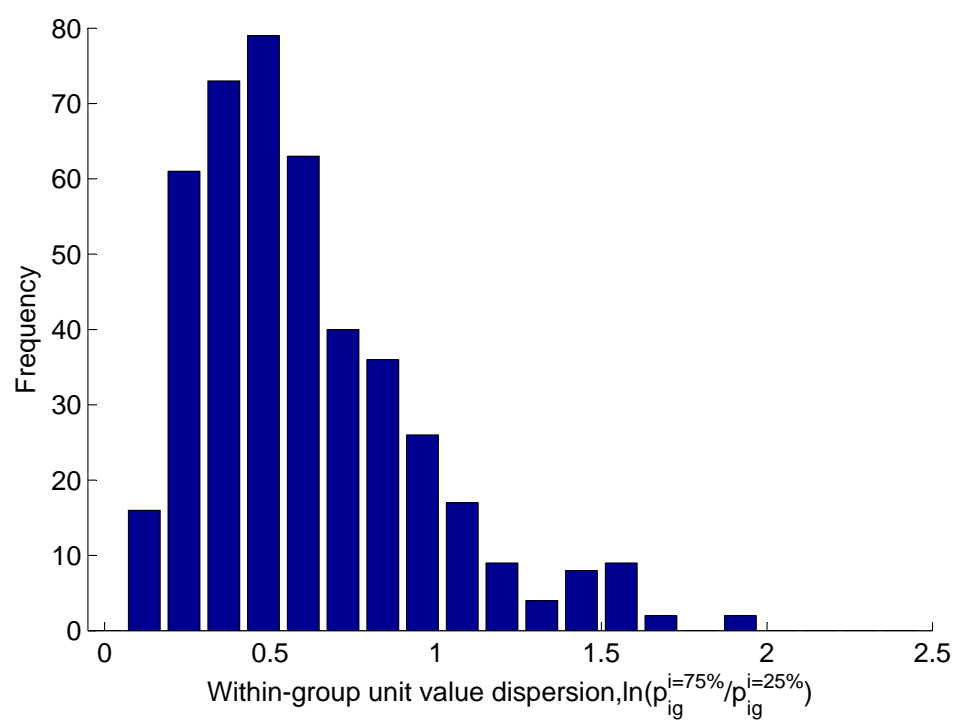

Notes: This figure plots the distribution of within product interquartile range unit values across all 4-digit product groups over the entire sample. The interquartile range of a given product group is defined as the difference between unit value of the items at the $75^{\text {th }}$ and $25^{\text {th }}$ percentiles of the product group, averaged over 20 quarters. 
Figure 10. Changes in Prices and Consumed Quantities between High/Low Unit Value Items: All Items and Select Subsets

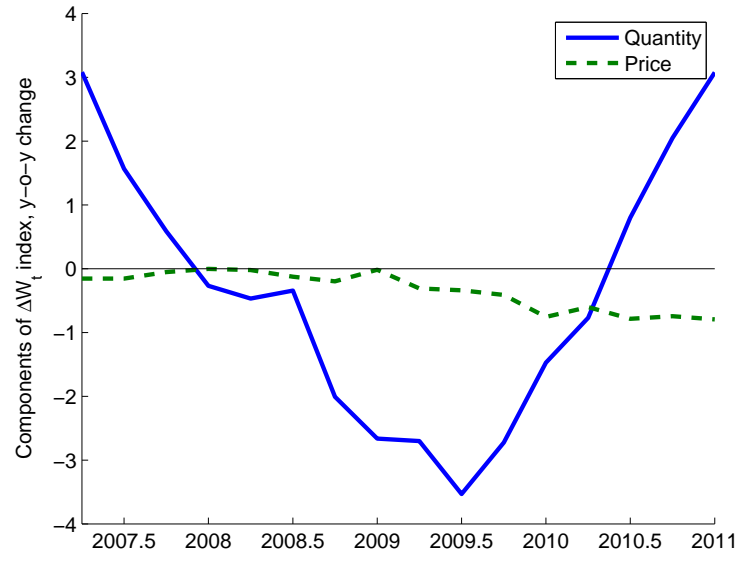

(a) All Items

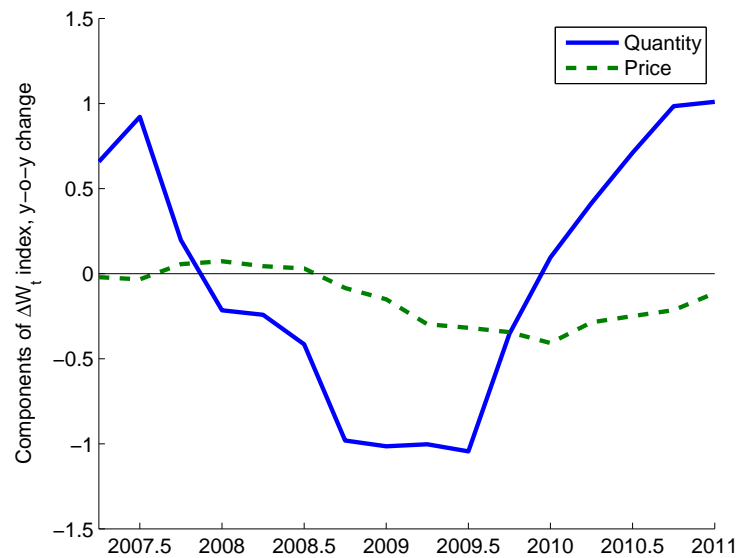

(c) Domestic Items

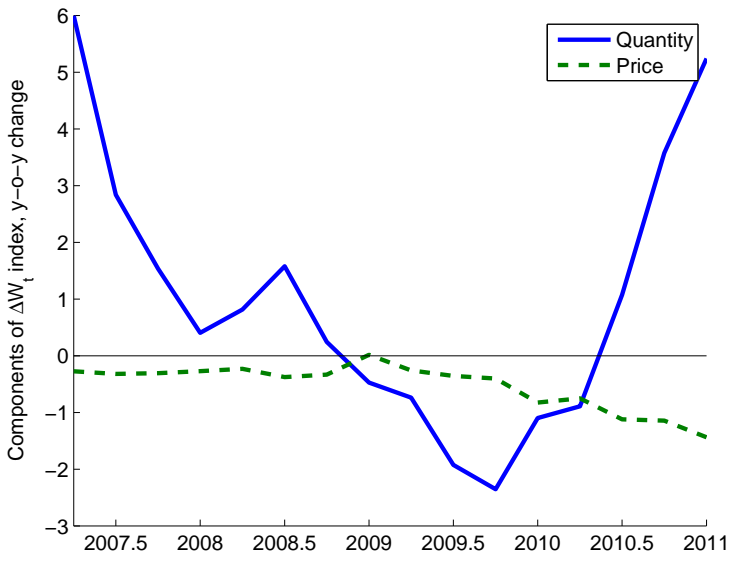

(b) Foreign items

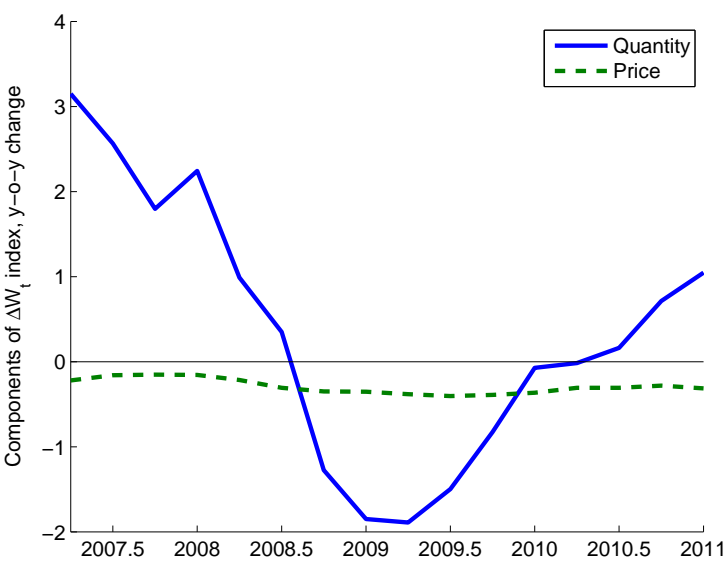

(d) Store products

Notes: This figure reports price and quantity share indexes that measure y-o-y shifts in relative prices and consumed quantities between high/low unit value items within 4-digit product groups. A negative value for the quantity index, defined as the quantity component of the index in (6), implies a systematic shift in quantities consumed towards lower unit value items. A positive value for the price index, defined as the price component of the index in (6), implies a systematic decease in the relative price of lower unit value items. The reported indexes aggregate results for product groups using each group's share in total F\&B expenditures. 
Figure 11. Distribution of Within Product Group Average Unit Value of Imported Items Relative to Domestic Items at the 4-Digit Product Code Level

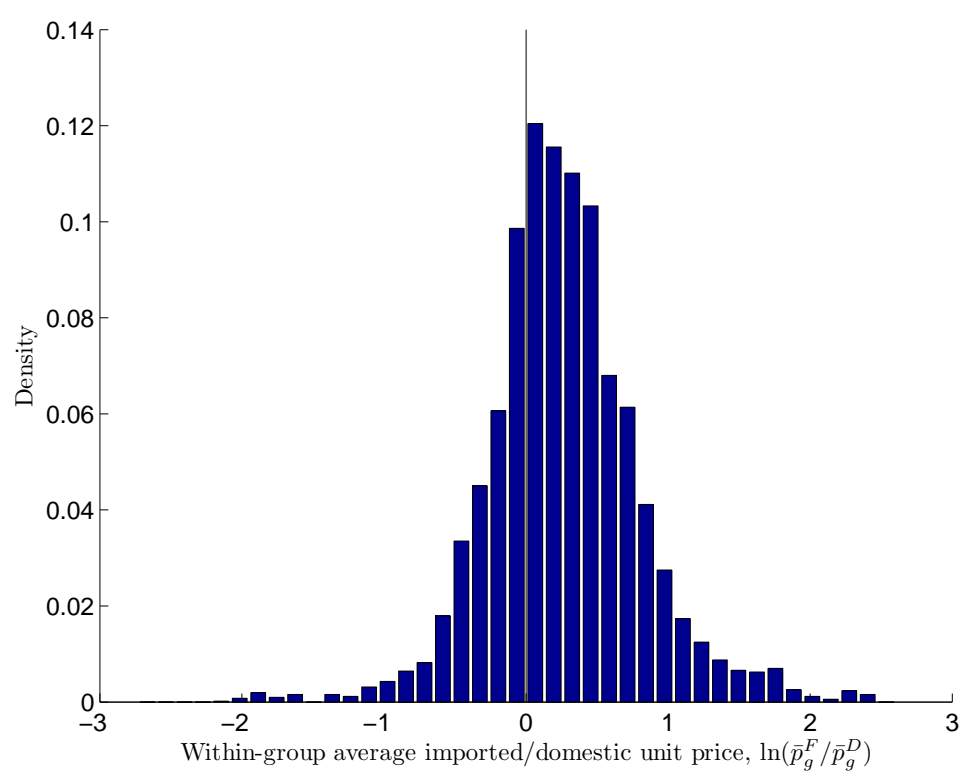

Notes: This figure plots the distribution of the average within-group unit values of foreign items relative to domestic items at the four-digit product code level. To construct the average relative unit value, we compute for each item in a product group the sample median relative unit value within a product group, $\bar{p}_{i g}$, based on available observations for $p_{i g t} / \bar{p}_{g t}$, where $p_{i g t}$ is the unit value for item $i$ in group $g$ at time $t$ and $\bar{p}_{g t}$ is defined below equation (6), and then compare the average unit value of imported and domestic goods in each product group, $\bar{p}_{g}^{F} / \bar{p}_{g}^{D}$. 
Figure 12. Changes in Consumed Quantities between High/Low Unit Value Items: Groups with Higher/Lower Average Domestic Unit Values

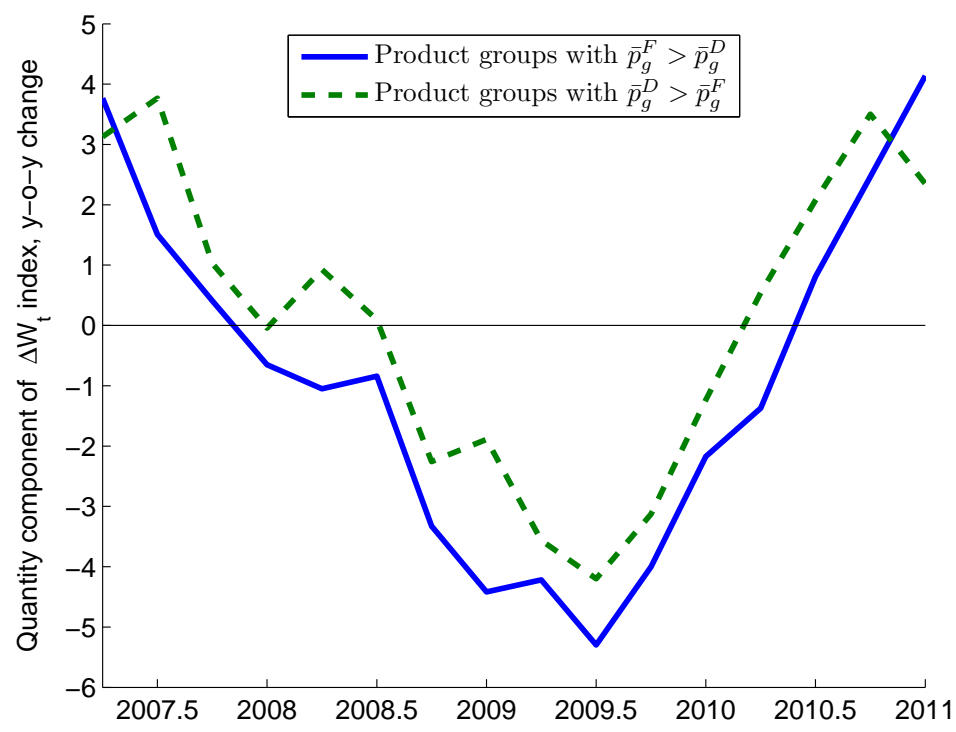

Notes: This figure reports a quantity component of the index in (6) separately for product groups with higher/lower average domestic unit values. A negative index value implies a systematic shift towards lower unit value items. The reported indexes are an expenditure weighted average of product group indexes.

Figure 13. Expenditure Switching between Composite Foreign and Domestic Goods

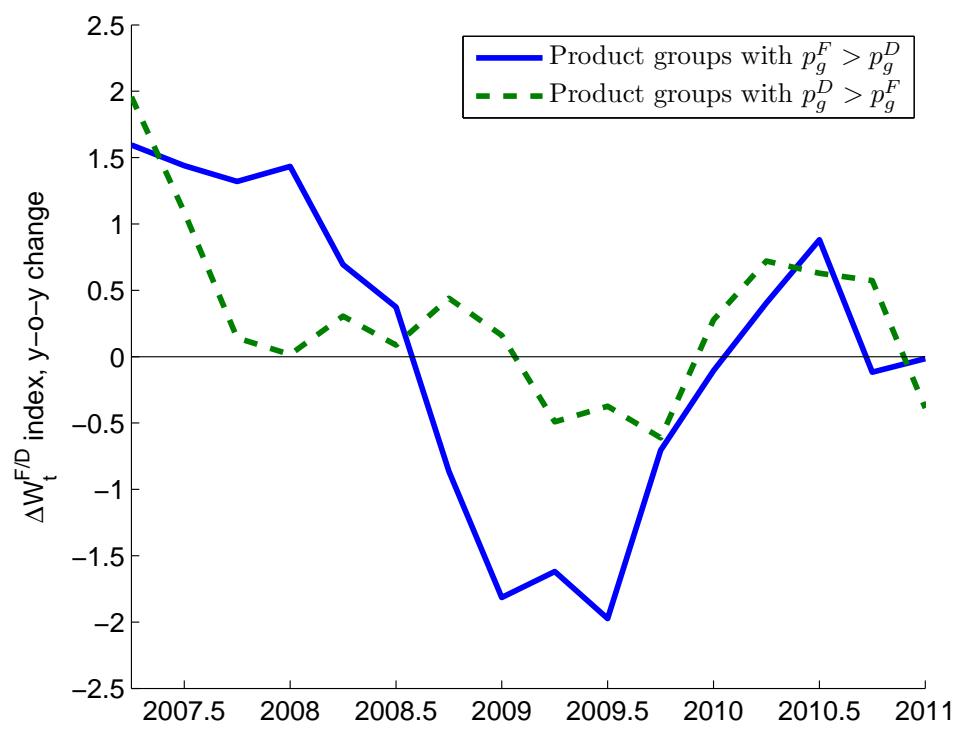

Notes: This figure reports an expenditure share index that measures y-o-y expenditure switching between composite foreign and domestic goods within 4-digit product groups. Index values are reported separately for (i) groups where the unit value of the composite foreign good exceed the unit value of the domestic counterpart and (ii) groups where the unit value of the composite domestic good exceed the unit value of the foreign counterpart. Group indexes are aggregated using expenditure shares. A negative index value for both indexes implies the shift of expenditures towards the less expensive composite good. 
Figure 14. Model Estimated and Actual Within Components of Expenditure Switching

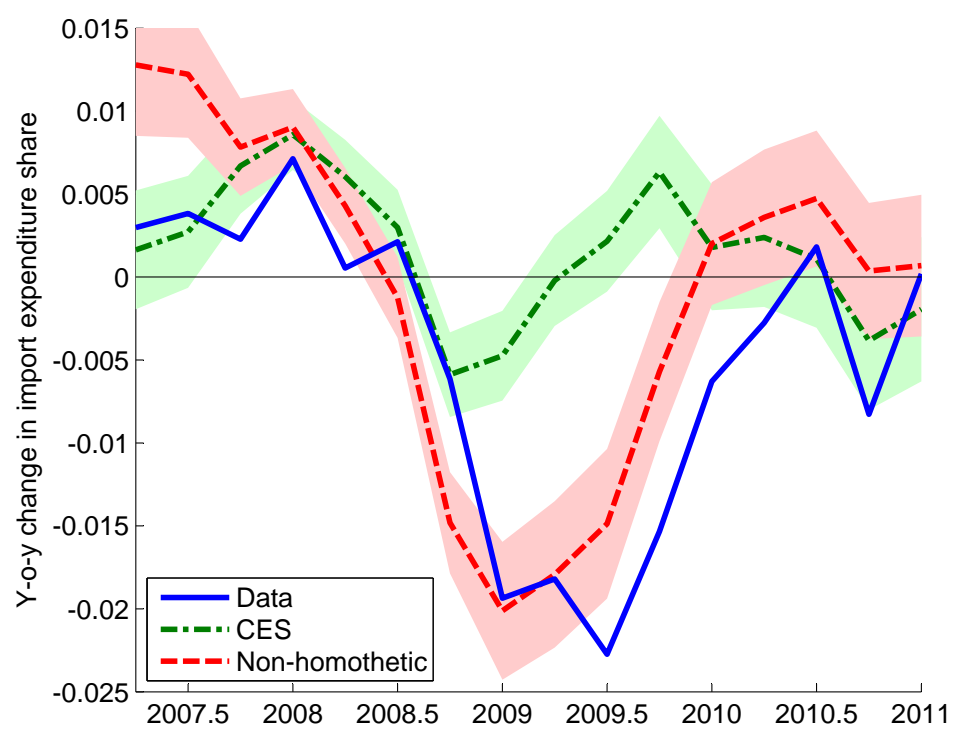

Notes: This figure plots the within component of expenditure switching observed in the data and estimated using the model based on (9), for the CES and Non-homothetic models. The shaded areas are two standard error bands, calculated analytically based on clustered standard errors at the group $\times$ time level.

Figure 15. Non-Homothetic Model's Within Components of Expenditure Switching: Income and Price Effects

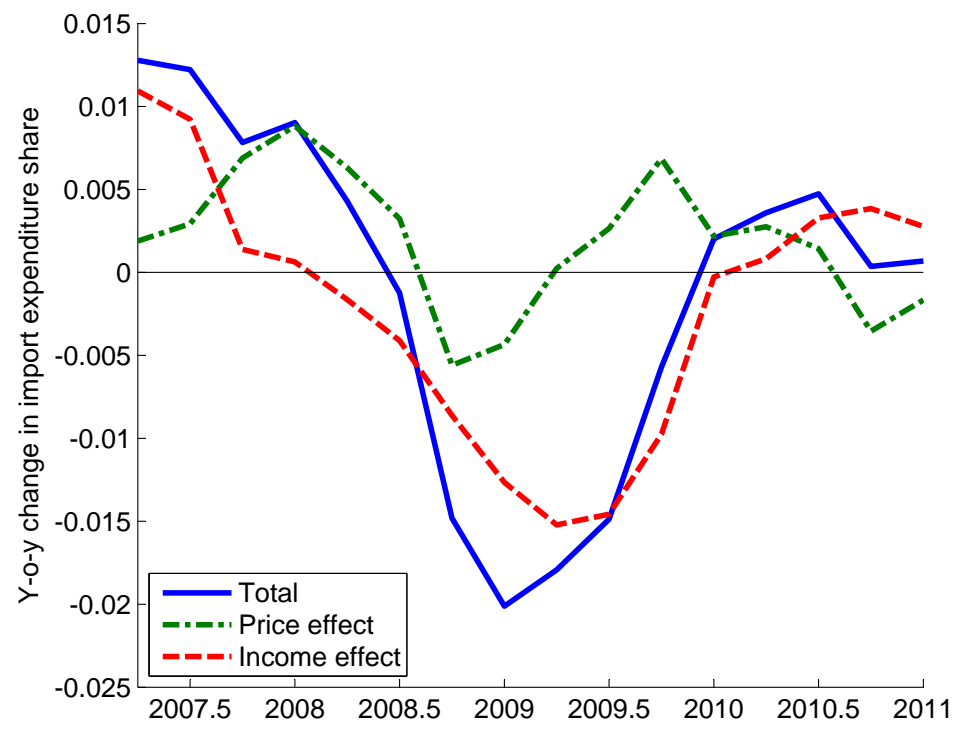

Notes: This figure plots the estimated within component of expenditure switching predicted by the nonhomothetic model, breaking it down into contributions due to (i) a price effect, and (ii) an income effect. The estimates are based on the full model (9). 


\section{Appendix Material \\ For Online Publication}




\section{Appendix A Role of Intensive and Extensive Margins in Ex- penditure Switching}

Given that we are using detailed item level data, we wish to investigate the potential impact of entry and exit of items on the dynamics of expenditures, both for domestic and foreign goods. There are two important reasons to do so. First, as recently shown by Corsetti et al. (2013), it is theoretically possible to have expenditure switching without a corresponding relative price change if there is substantial entry and exit of goods. Second, our modeling and estimation strategies in Section 4 rely on continuing items as the source of identification.

In order to examine the importance of entry and exit in our data, we follow two different strategies. First, we consider a gross concept, and look at the time series of items, aggregated by their domestic/foreign origin, for continuing, entering and exiting items. Figure A1 plots these time series for q-o-q data. The top panel graphs the count of UPC items, while the bottom panel plots the time series based on total expenditures. Regardless of the measure, continuing items make up the largest component of total of goods, both for domestic and foreign items, over time. Moreover, in terms of expenditures, continuing items capture the boom-bust cycle as well as the expenditure switching from imported to domestic items during the crisis.

Second, to more directly examine the role of entering/exiting versus continuing items in expenditure switching, we decompose the growth rate of expenditure switching into contributions from intensive and extensive margins. Borrowing from the methodology di Giovanni et al. (2014), we decompose a growth rate of a given variable, which is constructed using item $(i)$ and product group $(g)$ data. In particular, for simplicity we will consider the growth rate of total sales, $X_{t}$, which are the sum of individual item sales, $x_{i g t}$, where an item $i$ falls into a group $g$. We will consider the growth rate between $t-1$ and $t$.

The log-difference growth rate of total sales can be manipulated to obtain an (exact) decomposition into intensive and extensive components:

$$
\begin{aligned}
\tilde{\gamma}_{t} & \equiv \ln \sum_{i \in I_{t}} x_{i g t}-\ln \sum_{i \in I_{t-1}} x_{i g t-1} \\
& =\ln \frac{\sum_{i \in I_{t / t-1}} x_{i g t}}{\sum_{i \in I_{t / t-1}} x_{i g t-1}}-\left(\ln \frac{\sum_{i \in I_{t / t-1}} x_{i g t}}{\sum_{i \in I_{t}} x_{i g t}}-\ln \frac{\sum_{i \in I_{t / t-1}} x_{i g t-1}}{\sum_{i \in I_{t-1}} x_{i g t-1}}\right) \\
& =\underbrace{\gamma_{t}}_{\text {Intensive margin }}-\underbrace{\ln \frac{\pi_{t, t}}{\pi_{t, t-1}}}_{\text {Extensive margin }},
\end{aligned}
$$

where $I_{t / t-1}$ is the set of items sold in both $t$ and $t-1$ (the intensive sub-sample of items 
in year $t)$ and $\pi_{t, t}\left(\pi_{t, t-1}\right)$ is the share of items sold in this intensive sub-sample of goods in period $t(t-1)$. Entrants have a positive impact on growth while exiters push the growth rate down, and the net impact is proportional to the share of entrants'/exiters' sales in aggregate sales. ${ }^{41}$ Meanwhile, an observation only belongs to the intensive margin if an individual firm serves an individual destination in both periods.

The growth rate decomposition of total sales, (A.1), can be arbitrarily applied to total sales, total import sales, or total domestic sales in Latvia. This is the crucial point to consider when calculating the decomposition for the growth rate of expenditure switching. Let us define the share of imported items to total items for the overall economy at $t, s_{t}^{F}$ as:

$$
s_{t}^{F}=\frac{X_{t}^{F}}{X_{t}}
$$

where $X_{t}^{F}$ are total imports at $t$. Then the $(\log )$ growth rate of $s_{t}^{F}$ - i.e., the growth rate of expenditure switching - can be defined as a function of the growth rate of imports and total sales:

$$
\begin{aligned}
\ln s_{t}^{F} & =\ln X_{t}^{F}-\ln X_{t} \\
& =\ln \sum_{i \in I_{t}} x_{i g t}^{F}-\ln \sum_{i \in I_{t}} x_{i g t} .
\end{aligned}
$$

Therefore, the growth rate of $s_{t}^{F}$ between $t-1$ and $t$ is:

$$
\begin{aligned}
\ln s_{t}^{F}-\ln s_{t-1}^{F} & =\left(\ln \sum_{i \in I_{t}} x_{i g t}^{F}-\ln \sum_{i \in I_{t}} x_{i g t}\right)-\left(\ln \sum_{i \in I_{t-1}} x_{i g t-1}^{F}-\ln \sum_{i \in I_{t-1}} x_{i g t-1}\right) \\
& =\left(\ln \sum_{i \in I_{t}} x_{i g t}^{F}-\ln \sum_{i \in I_{t-1}} x_{i g t-1}^{F}\right)-\left(\ln \sum_{i \in I_{t}} x_{i g t}-\ln \sum_{i \in I_{t-1}} x_{i g t-1}\right) \\
& =\tilde{\gamma}_{t}^{F}-\tilde{\gamma}_{t} .
\end{aligned}
$$

We can therefore apply the decomposition (A.1) to the total growth rate of imports $\left(\tilde{\gamma}_{A t}^{F}\right)$ and total sales $\left(\tilde{\gamma}_{A t}\right)$, and take their difference to obtain an exact decomposition of the intensive and extensive components of the growth rate of expenditure switching over time.

We calculate the overall, intensive and extensive growth rates from q-o-q growth in expenditure switching and then sum the growth rates over a four-quarter overlapping rolling window, in order to avoid seasonality. Figure A2 plots the results. First, the import expenditure share fell by around $10 \%$ during the crisis. Since imports account for slight

\footnotetext{
${ }^{41}$ This decomposition follows the same logic as the decomposition of price indices proposed by Feenstra (1994).
} 
more than $1 / 3$ of expenditures, this fall in imports is consistent with a $3.8 \%$ of expenditures allocated towards domestic items, Second, the intensive component tracks very closely the growth rate of the aggregate expenditure switching during the crisis. Third, the growth rate of the extensive component during the crisis is relatively flat and positive, indicating a small but persistent switching of expenditures towards imported rather than domestic items. All in all, this decomposition assuages our concern that ignoring the extensive margin in our analysis will lead to any misleading conclusions.

\section{Appendix B Decomposition of the Within Expenditure Switch- ing: Within/Across Store Components}

This appendix further decomposes expenditure switching within product groups into switching within/across store types. Expenditure switching within a product group $g$ can be expressed as

$$
\varphi_{g t}^{F}-\varphi_{g k}^{F}=\sum_{v} m_{g v t} \varphi_{g v t}^{F}-\sum_{v} m_{g v k} \varphi_{g v k}^{F}
$$

where $v=\{H, S, D\}$ indexes the three store types in our dataset, $m_{g v t}$ is the share of store $v$ in total expenditures on group $g$ in period $t$ and $\varphi_{g v k}^{F}$ is the share of imports in product group $g$ and store $v$ at time $t$.

We can then decompose expenditure switching within a product group $g$ as

$$
\varphi_{g t}^{F}-\varphi_{g k}^{F}=\underbrace{\sum_{v} m_{g v k}\left(\varphi_{g v t}^{F}-\varphi_{g v k}^{F}\right)}_{\text {Within stores }}+\underbrace{\sum_{v} \varphi_{g v k}^{F}\left(m_{g v t}-m_{g v k}\right)}_{\text {Across stores }}+\sum_{v} \Delta \varphi_{g v t}^{F} \Delta m_{g v t} .
$$

Aggregate expenditure switching within product groups, as defined by the first term on the right hand side of equation (1), can then be decomposed into within and across store types as

$$
\begin{aligned}
\underbrace{\sum_{g} s_{g k}\left(\varphi_{g t}^{F}-\varphi_{g k}^{F}\right)}_{\text {Within groups }} & =\underbrace{\sum_{g} s_{g k} \sum_{v} m_{g v k}\left(\varphi_{g v t}^{F}-\varphi_{g v k}^{F}\right)}_{\text {Within stores }}+\underbrace{\sum_{g} s_{g k} \sum_{v} \varphi_{g v k}^{F}\left(m_{g v t}-m_{g v k}\right)}_{\text {Across stores }} \\
& +\underbrace{\sum_{g} s_{g k} \sum_{v} \Delta \varphi_{g v t}^{F} \Delta m_{g v t}}_{\approx 0} .
\end{aligned}
$$

The above equation decomposes the overall within contribution to expenditure switching into two subcomponents: (i) within groups and within a store type, and (ii) within groups, but across store types. Similar to the decomposition of aggregate expenditure switching in equation (1), the within/within margin contributes directly to within expenditure switching, as consumers substitute between domestic and imported goods within a product group and 
a particular store type. Within/across expenditure switching can contribute indirectly if consumers reallocate expenditures across stores and groups' import shares across stores differ.

The decomposition results are reported in Figure A3 and show that the within expenditure switching took place almost entirely within store types. We further find that switching within each of the three store types contributed similarly to the overall expenditure switching. The across store component contributed less than $10 \%$ to the overall switching within 4-digit product groups.

This finding is not surprising when interpreted in terms of savings that consumers could make by switching across items within a product group in a given store as opposed to switching across stores. Specifically, by comparing prices across store types, we find that in Supermarkets and Hypermarkets $70 \%$ of monthly prices of overlapping UPCs items are identical, and in $97 \%$ of cases the deviation in prices is less than $5 \%$. The mean item price in Supermarkets is only $0.07 \%$ below the corresponding price in the Hypermarket. Prices in Discounter stores are on average 12.7\% lower than in Supermarkets and Hypermarkets, while the median UPC item is $10.6 \%$ cheaper. These price differentials imply a small margin for savings when compared to the within group/within store item price dispersion, which we discuss in Section 3.3.

Looking further into the contributing factors to the limited overall switching across store types, we find some systematic differences in import shares across stores. Aggregate imports shares for Discounter stores, Supermarkets and Hypermarkets are 0.30, 0.41 and 0.50, respectively. However, shares of the three store types in total expenditures by product groups did not vary systematically during the crisis.

\section{Appendix C Demand Model and Estimation Derivation}

\section{C.1 Setup}

Define the expenditure allocation problem over $\mathrm{F} \& \mathrm{~B}$ for a representative consumer as

$$
\begin{gathered}
\max _{\left\{c_{i g t}\right\}} U_{t}=\left(\sum_{g} \omega_{g}^{\frac{1}{\rho}} c_{g t}^{\frac{\rho-1}{\rho}}\right)^{\frac{\rho}{\rho-1}} \\
c_{g t}=\left(\left(\frac{1}{N_{g t}}\right)^{\frac{1}{\sigma_{g}}} \sum_{i \in I_{g t}} \widehat{c}_{i g t}^{\frac{\sigma_{g}-1}{\sigma_{g}}}\right)^{\frac{\sigma_{g}}{\sigma_{g}-1}}, \text { where } \widehat{c}_{i g t}=\theta_{i g}^{\lambda_{g}\left(C_{t}\right)} c_{i g t}
\end{gathered}
$$


s.t.

$$
\sum_{g} \sum_{i} p_{i g t} c_{i g t}=C_{t}
$$

Utility is defined over $G$ product groups with the familiar CES aggregator. Within each product group $g$ a consumer chooses between a group-specific set of items (there are $N_{g t}$ items), each denoted $\widehat{c}_{i g t}$, measured in 'utils,' and constructed as $\widehat{c}_{i g t}=\theta_{i g}^{\lambda_{g}\left(C_{t}\right)} c_{i g t}$, where $c_{i g t}$ is measured in common physical units (e.g., KG or L) and $\theta_{i g}$ is a factor that converts physical units into 'utils.' In Hallak (2006), $\theta_{i g}$ is as a proxy for quality differences and is measured using export unit values. We follow the same strategy using the UPC-level unit values, though as discussed above, there might be other factors driving the difference in unit values than just quality. Furthermore, as in Hallak (2006), we allow $\theta_{i g}$ to vary with income level (measured as total expenditures $C_{t}$ ), so that the degree to which "quality differences" within a product group matter is an increasing function of income. Specifically, $\lambda_{g}\left(C_{t}\right)$ captures the consumer's intensity for demand of an item's "quality" in a given group $g$, and varies with income $C_{t}$ such that $\partial \lambda_{g}\left(C_{t}\right) / \partial C_{t}>0$. It is worth stressing again that the specified model does not differentiate between domestic and foreign goods within a product group. We also allow for the elasticity of substitution between items within a group, $\sigma_{g}$, and the number of items within a group $N_{g}$, to vary by product group.

\section{C.2 Characterization of the Model Solution}

Given prices, $p_{i g t}$, total expenditure, $C_{t}$, qualities, $\theta_{i g}$, and parameter values, the consumer optimally allocates food expenditures in each period. Because modifications to the standard CES utility function rely entirely on exogenous parameters, the familiar first-order conditions hold both at the top and bottom levels of the utility. Specifically, at the top level we have

$$
c_{g t}=\omega_{g} P_{g t}^{-\rho} C_{t},
$$

and consistent with the expenditure share notation in the previous section, group $g$ 's expenditure share can be written as

$$
s_{g t} \equiv \frac{P_{g t} c_{g t}}{C_{t}}=\omega_{g} P_{g t}^{1-\rho} .
$$

The utility-based aggregate price index, which we use as a numéraire, is

$$
P_{t}=\left(\sum_{g} \omega_{g} P_{g t}^{1-\rho}\right)^{\frac{1}{1-\rho}}
$$


At the bottom level of the utility, i.e., within product groups, the demand equation is

$$
c_{i g t}=\frac{1}{N_{g t} \theta_{i g}^{\lambda_{g}\left(C_{t}\right)}}\left(\frac{\frac{p_{i g t}}{\theta_{i g}^{\lambda_{g}\left(C_{t}\right)}}}{P_{g t}}\right)^{-\sigma_{g}} c_{g t},
$$

so that an item's within-group expenditure share is

$$
\varphi_{i g t} \equiv \frac{p_{i g t} c_{i g t}}{P_{g t} c_{g t}}=\frac{1}{N_{g t}}\left(\frac{\frac{p_{i g t}}{\theta_{i g}^{\lambda\left(C_{t}\right)}}}{P_{g t}}\right)^{1-\sigma_{g}}
$$

and the item's expenditure share in total $\mathrm{F} \& \mathrm{~B}$ expenditures is

$$
s_{i g t} \equiv \varphi_{i g t} s_{g t}=\frac{1}{N_{g t}}\left(\frac{\frac{p_{i g t}}{\theta_{i g}^{\lambda g\left(C_{t}\right)}}}{P_{g t}}\right)^{1-\sigma_{g}} \omega_{g} P_{g t}^{1-\rho} .
$$

Finally, the utility-based price index for a product group is

$$
P_{g t}=\left(\frac{1}{N_{g t}} \sum_{i}\left(\frac{p_{i g t}}{\theta_{i g}^{\lambda_{g}\left(C_{t}\right)}}\right)^{1-\sigma_{g}}\right)^{\frac{1}{1-\sigma_{g}}}
$$

It is instructive to note that if the income level and quality considerations are switched off, i.e., $\lambda_{g}\left(C_{t}\right)=0$, then the equation for $s_{i g t}$ collapses to

$$
s_{i g t}=\frac{1}{N_{g t}}\left(\frac{p_{i g t}}{P_{g t}}\right)^{1-\sigma_{g}} \omega_{g} P_{g t}^{1-\rho},
$$

which is the standard CES expression for the item's expenditure share in total expenditures. However, more generally income affects the expenditure share, so that the demand system is non-homothetic.

Equilibrium: Given prices, $p_{i g t}$, total expenditure, $C_{t}$, qualities, $\theta_{i g}$, and parameter values, a consumer optimally allocates food expenditures in each period. The solution of the demand system can be characterized by a system of expenditure share equations sigt, combined with group and aggregate price indexes and the budget constraint. One can solve the system to obtain the optimal consumption quantities for each item, $c_{i g t}$.

\section{C.3 Estimation Equation}

The key equation that characterizes the solution of the model presented in the previous section is (C.3). In order to take the model to the item-level data, we use the log first difference of an item's share $\left(\Delta \ln s_{i g t}\right)$ rather than its level. This change of variable, along with 
fixed effects helps us deal with several econometric problems that may bias our estimates. ${ }^{42}$ We will discuss these issues in detail below.

First, log-differencing (C.3) and substituting in (C.1), we arrive at

$$
\Delta \ln \varphi_{i g t}=\Delta \ln N_{g t}+\left(1-\sigma_{g}\right) \Delta \ln \left(\frac{p_{i g t}}{P_{g t}}\right)+\left(\sigma_{g}-1\right) \Delta \lambda_{g}\left(C_{t}\right) \ln \theta_{i g} .
$$

To allow for estimation of (C.5), we need to take a stand on the functional form of $\lambda_{g}\left(C_{t}\right)$. As a baseline, we follow Hallak (2006), and assume that the quality parameter is linear in the $\log$ of total expenditures: $\lambda_{g}\left(C_{t}\right)=\eta_{g}+\mu_{g} \ln C_{t}$. We allow for heterogeneity in the average intensity of demand for quality of items in a group $\left(\eta_{g}\right)$, as well as for the impact of income on quality demand across groups $\left(\mu_{g}\right)$. We then rewrite (C.5) as

$$
\Delta \ln \varphi_{i g t}=\Delta \ln N_{g t}+\left(1-\sigma_{g}\right) \Delta \ln \left(\frac{p_{i g t}}{P_{g t}}\right)+\left(\sigma_{g}-1\right) \mu_{g} \ln \theta_{i g} \Delta \ln C_{t},
$$

where the $\eta_{g}$ disappears from taking first differences, and since the aggregate price index, $P_{t}$, is the numéraire, $C_{t}$ is expressed in real terms.

\section{Appendix D Identification and Additional Demand Estima- tion Results}

\section{D.1 Identification}

The demand estimation presented in Section 4.1 faces several identification issues, which we discuss in this subsection, and address in further estimation results in the following subsection. First, rather than using the model-implied price index to derive group-level prices as a function of the item level prices, we compute the price indexes at the group level with the Törnqvist index. This approach may lead to measurement error due to unaccounted income-driven substitution, which would be picked up by the model-based group price index of (C.4). However, since $\Delta \ln P_{g t}$ enters the estimating equation linearly (both in the relative price and in deflating total expenditures), we eliminate this potential bias by including fixed effects that vary at the product group $\times$ time dimension.

Second, several papers have made the argument that trade costs went up during the crisis due to the freezing of trade credit, which made international trade more costly (Ahn

\footnotetext{
${ }^{42}$ Note that by studying the growth rate of shares we are implicitly ignoring the impact of entry and exit on expenditure switching. We are not concerned with this omission given the importance of intensive margin - and correspondingly small role of the extensive margin - highlighted in Finding 1 of Section 3. Furthermore, we are able to control for changes in the number of items per product group each period by using appropriate fixed effects.
} 
et al., 2011). Some firms (either domestic or foreign) may also have been driven out of business, thereby impacting the price level and supply of goods in a given product group. Furthermore, domestic and foreign goods within a given product group may also differ along other dimensions, such as durability or distribution (general availability) in the stores. All these differences between domestic and foreign goods may bias the estimation of (9). To control for these potential biases, we also consider a more demanding set of fixed effects, which are at the product group $\times$ origin $\times$ time level, where the origin is a dummy variable equal to one if the good is domestic, and zero if it is foreign. ${ }^{43}$ The inclusion of these fixed effects will control for any unobserved heterogeneity of domestic and foreign items at the product group level. These effects will also control for potential shocks at a very disaggregated level in order to capture the general equilibrium impact of the shocks within a product group, and differential impacts of these shocks on domestic and foreign goods.

We also address the possibility that firms will discriminate their pricing depending on item-level characteristics. For example, firms may set prices higher for more desirable items (which are also more expensive), and pricing behavior may not respond to shocks symmetrically over time across different types of goods. Furthermore, other unobserved item-level characteristics (e.g., durability) might also bias the estimated price and income coefficients. To account for these potential biases, we augment (9) with item-level fixed effects in an additional regression specification.

Including both item-level and product group $\times$ time fixed effects deal with many potential omitted variables and unobserved shocks at very disaggregated levels. However, it is still possible that the unobserved demand shocks $\left(\varepsilon_{i g t}\right)$ are correlated with price changes over time at the item level. Furthermore, it is possible that there are other factors at work, which lower consumer's propensity to buy imports, regardless of relative price changes, which would bias our estimation results. For example, Latvians may have become more "patriotic" during the crisis, and thus slanted their consumption to domestic goods. We therefore adopt two instrumental variables strategies using subsets of the data as further checks.

The first approach exploits the variation in bilateral exchange rates for different foreign items as cost shocks. Though we are looking at retail prices, there is evidence that exchange rates pass-through to the consumer level and can serve as viable instruments at the retail level by providing a plausible source of exogenous price variation (e.g., see Campa and Goldberg, 2006; Goldberg and Hellerstein, 2008; Nakamura and Zeron, 2010). Although

\footnotetext{
${ }^{43}$ In other words, we replace $\alpha_{g t}$ with product group $\times$ origin $\times$ time fixed effects, $\alpha_{\text {got }}$.
} 
Latvia maintained a fixed exchange rate to the euro throughout the sample period, it had floating exchange rates with a significant share of importers. ${ }^{44}$ We can therefore exploit variation in exchange rate movements across time and trading partners within a given product group with multiple foreign items. We also exploit heterogeneity in pass-through at the item level by interacting the exchange rate changes with an item's average unit value, since pass-through may vary for cheap and expensive goods. Therefore, the IV strategy exploits both cross-sectional and time-series variations in the data. Specifically, we instrument the item-level price changes with six lags of nominal exchange rate changes, and the interaction of these changes with the average unit value. ${ }^{45}$

The second approach follows Hausman (1996) and instruments Latvian goods' price changes with price changes of the same items in another market (so called "Hausman instruments"). In particular, we restrict our sample to a set of Latvian-produced goods that we also have price changes for in Estonia, Latvia's neighboring country. As long as item-level demand shocks are uncorrelated across countries, this strategy will help deal with potential biases - for example, it will deal with issues such as "patriotism" affecting Latvians' consumption patterns during the crisis, which would have led to increased consumption of Latvian goods, irrespective of relative price changes. It is important to note that the inclusion of product group $\times$ time effects pick up any common shocks hitting both Estonia and Latvia at more macro levels.

\section{D.2 Additional Heterogeneous Coefficient Results}

Besides our core results reported in Table 6 for the heterogeneous coefficient regressions, we also allow for the possibilities of non-linearities in the income effect and explore more stringent sets of fixed effects. Table A1 presents our core results for the weighted-mean coefficients from these regressions, where columns (1) and (2) replicate the main results in Table 6. Next, column (3) allows for the possibility of a non-linear income effect by including a squared term of the change in aggregate real consumption interacted with quality. The coefficient for the non-linear term is insignificant, while the estimated price and income

\footnotetext{
${ }^{44}$ The foreign sample includes imports from 40 countries, out of which 24 have floating exchange rates with Latvia. These 24 countries accounted for $40 \%$ of imports in our sample, with Poland, Russia and Sweden being the largest non-euro trading partners. For the median non-euro trading partner, the quarterly exchange rate viz. Lats fluctuated in the range of $34 \%$ on average over the sample period - the ranges for Poland, Russia and Sweden were $36 \%, 32 \%$ and $24 \%$, respectively.

${ }^{45}$ The first-stage regression is $\Delta \ln \left(p_{i g t} / P_{g t}\right)=\alpha_{g t}+\beta \ln \bar{p}_{i g}+\sum_{k=1}^{6} \delta_{k} \Delta N E R_{t-k}^{i}+$ $\sum_{k=1}^{6} \gamma_{k} \ln \bar{p}_{i g} \Delta N E R_{t-k}^{i}+\epsilon_{i g t}$, where $\Delta N E R_{t-k}^{i}$ is the quarterly nominal exchange rate change of the Lat vs. the currency of country that item $i$ is shipped from, lagged $t-k$ quarters, with $k=1, \ldots, 6$. The cutoff of 6 quarters was chosen given further lags did not increase fit, nor were significant.
} 
coefficients do not differ significantly from the baseline estimates in column (2). Therefore, it does not appear that non-linearities are a concern. We next control for the possibility that domestic suppliers reacted differently than foreign ones during the boom and ensuing crisis. For example, data show that producers in Latvia responded to the severe crisis by cutting production costs (e.g., wages), which may have lowered prices of domestic final goods, including food items, relative to their imported counterparts (Blanchard et al., 2013; Kang and Shambaugh, 2013a). Furthermore, there may be unobserved time-varying differences between domestic and foreign goods within the narrowly defined product groups, which would bias our results, as discussed above. To investigate these possibilities, we re-estimate the NH model controlling for product group $\times$ origin $\times$ time fixed effects. These results are presented in column (4). The estimated relative price coefficients increase (in absolute value) relative to the coefficients in the baseline estimations of column (2), but the difference is marginal. The estimated income coefficient is smaller than that of the baseline estimation, but this difference is again marginal and statistically indistinguishable from zero. Column (5) next controls for item-level fixed effects in order to capture omitted time-invariant itemlevel characteristics. Controlling for these fixed effects increases the magnitude of the price coefficient, and decreases the income coefficient relative to the baseline estimation of column (2). This confirms the potential of estimation bias of the demand equation, but neither the price nor income coefficients vary dramatically in magnitude across columns (2) and (5).

\section{D.3 Pooled Coefficient Results}

We also explore restricting the price and income coefficients to being homogeneous (i.e., $\beta_{1 g}=\beta_{1} \forall g$, and $\beta_{2 g}=\beta_{2} \forall g$ ), in order to study whether results differ substantially from the heterogeneous coefficient estimates of Table 6 and Table A1. Table A2 presents our baseline estimations. Column (1) presents the CES model, where we only consider relative price changes and ignore potential income effects. The estimated coefficient is -2.390 , and is significant at the $1 \%$ level. This coefficient implies a price elasticity, $\sigma$, equal to $3.390 .{ }^{46}$ Column (2) presents the baseline results for the $\mathrm{NH}$ model. The estimated $\beta_{2}$ coefficient is positive and significant, with a value of 1.104 , which implies a value of $\mu$ equal to 0.464 . Columns (3)-(5) next present additional controls as in the heterogeneous coefficient results in Table A1 - the pooled estimates are similar to the specifications for our main regression results.

\footnotetext{
${ }^{46}$ This elasticity is the same order of magnitude compared to previous estimates using retail level prices, such as for the coffee market (Nakamura and Zeron, 2010), or using scanner data across many goods (Handbury, 2013).
} 


\section{D.4 Instrumental Variables and Robustness Checks}

Table A3 presents instrumental variable estimates for two sub-samples of data. Panel A uses data for the sample of imported items from non-euro countries, and exploits exchange rate variation with these trading partners. ${ }^{47}$ The first two columns show results for the CES specification, while the latter two for the NH specification. Columns (1) and (3) run OLS regressions in order to compare with their IV counterparts in columns (2) and (4), respectively. Both sets of IV results have larger prices elasticities compared to the OLS ones (which are similar in magnitude to the estimates for the whole sample in Table A2), and are significant. Turning to the income elasticity in column (4), the IV estimate decreases slightly relative to the OLS one in column (3), but the difference is statistically indistinguishable from zero. Panel B next considers the subset of domestic goods that are also sold in Estonia, and uses the Estonian price change as the instrument. ${ }^{48}$ This is a much smaller set of goods than the pooled sample, but we still have sufficient power to identify the impact of relative price changes and income on the within-group variation of expenditure shares. Again, we present OLS and IV estimates for the reduced sample for both the CES and NH models. Similar to the findings in Panel A, the CES and NH IV relative price coefficients are larger (in absolute value) than their OLS counterparts. Further, the income coefficient in column (4) is larger than the OLS one, while both coefficients are significant at the $10 \%$ level. Interestingly, the estimated coefficients are of the same order of magnitude relative to what we find in the other samples of data, and the income coefficients are not statistically different from each other.

In sum, the IV results across the two sub-samples broadly support the estimated income effects of the OLS regressions of Table A2, while the price elasticities are larger in absolute value. We explore the quantitative implications of the larger price elasticities in Section D.5, by comparing the predicted expenditure switching during the crisis using both the IV estimates and the baseline OLS coefficients estimated using the full sample of data.

Finally, Table A4 presents results for the baseline pooled NH regression model for a variety of sample splits, as well as investigating heterogeneity across different product group characteristics. In particular, we split the data by (i) domestic vs. foreign items (columns

\footnotetext{
${ }^{47}$ The long-run pass-through coefficient for the average unit value item, calculated as $\sum_{k=1}^{6}\left(\hat{\delta}_{k}+\ln \bar{p} \hat{\gamma}_{k}\right)$, is -0.05 (s.e. $=0.022$ ) reflecting that a depreciation of the Lats leads to a price increase. Given that we are looking at retail prices, a small pass-through coefficient is not surprising (e.g., due to a large non-tradable component, see Burstein et al., 2005), but the null of weak instruments is rejected at conventional levels of significance, and the R-squared of the first-stage regression is 0.16 .

${ }^{48}$ The first-stage coefficient for Estonian price changes is 0.13 (s.e. $=0.013$ ), and the R-squared of the regression is 0.34 . The null of weak instruments are rejected at conventional levels of significance.
} 
(1) and (2)); (ii) types of stores (columns (3)-(5)); ${ }^{49}$ and (iii) different non-parametric specifications to check for non-linear effects of relative price changes and income, where we interact quartiles defined by (a) product group foreign shares (column (6)); (b) variation of item-level unit values within a product group (column(7)); (c) average item-level unit values across product groups (column (8)), and (d) average difference in foreign and domestic unit values within a group (column (9)). In sum, all income and price coefficients are comparable to the baseline estimates throughout all the different cuts of the data.

\section{D.5 Pooled Estimation Predictions}

We provide a back-of-the-envelope calculation that applies the pooled estimation coefficients to predict aggregate expenditure switching during the crisis period. This exercise allows us to examine different bounds for the role of income-induced expenditure switching, given the IV estimates. For the back-of-the-envelope calculation, we draw on information from Section 3, along with moments from the data used in our regression analysis. In particular, according to Finding 2 the relative price change for imported goods was 0.004 . The average relative unit value $\left(\ln \bar{p}_{i g}\right)$ for foreign items was 0.25 over the crisis period, and the change in real consumption per capita $\left(\Delta \ln C_{t}\right)$ was -0.13 . Next, we use coefficients from our baseline estimate in column (3) of Table A2, and compare the predicted within-group expenditure switching with the one based on the most conservative coefficient estimates, which are the IV estimates from column (4) of Table A3.

The results for the quantification exercises are presented in Table A5, where Panel A presents the results based on the OLS coefficients, and Panel B's numbers are based on the IV estimates. The first column displays the coefficient estimates, while column (2) presents the predicted expenditure switching (and associated standard errors) for the (i) price effect, (ii) income effect, and (iii) total. Column (3) displays the share of expenditure switching that the price and income effects account for, along with their standard errors. The total predicted expenditure switching is very similar using both sets of estimates $(-0.047$ and -0.046 for the OLS and IV coefficients, respectively). Turning to the decompositions, the income effect explains roughly $78 \%$ of total expenditure switching based on the OLS coefficients. Given the potential estimation bias, this may be viewed as an upper bound. However, turning to the results based on the IV estimation, where the price elasticity is more than 1.5 times the size of the OLS estimate and the income coefficient is $20 \%$ smaller

\footnotetext{
${ }^{49}$ This specification checks whether results are not simply being driven by consumers switching across stores as in Coibion et al. (2015).
} 
than it's OLS counterpart, one sees that the income effect still explains $63 \%$ of the predicted expenditure switching. Therefore, and as we shall see in the following section, the income effect plays an important role in driving expenditure switching within product groups.

\section{Appendix E Predicted Aggregate Within Expenditure Switch- ing and Standard Errors}

The section outlines how we calculate the aggregated predicted expenditure switching, along with corresponding standard error bands. We first define the predicted value of the item share that we obtain from the regression (9). In particular, we are only interested in the predicted value due to either the change in prices or the change in income (quality effect) or both, so let $\beta_{g} \equiv\left[\beta_{1 g}, \beta_{2 g}\right]$, and $Z_{i g t} \equiv\left[\Delta\left(p_{i g t} / P_{g t}\right), \ln \bar{p}_{i g} \times \Delta C_{t}\right]^{\prime}$, and ignore the group $\times$ time fixed effects.

Specifically, we predict the aggregate within-group y-on-y expenditure switching using coefficient estimates of the regression model (9), allowing for coefficient heterogeneity in the $\beta$ s across product groups. We use the full distributions of estimated coefficients to calculate the predicted expenditure switching between any consecutive quarters $\tau$ and $\tau-1$ :

$$
\left(\widehat{s_{\tau}^{F-s_{\tau-1}^{F}}}\right)^{\text {Within }}=\sum_{g} s_{g \tau-1}\left(\widehat{\varphi}_{g \tau}^{F}-\varphi_{g \tau-1}^{F}\right)
$$

where $\widehat{\varphi}_{g \tau}^{F}$ is generated using the following methodology:

1. Take the estimated coefficients from the within-group regressions (9), $\widehat{\beta}_{1 g} \mathrm{~s}$ and $\widehat{\beta}_{2 g} \mathrm{~s}$, and predict the quarterly growth rate of every item $i$ 's share in group $g$ sales $\Rightarrow$ $\widehat{\Delta \ln \varphi_{i g \tau}}$.

2. Use the quarterly growth rate to calculate the $\tau$ share of item $i$ conditional on the item's share at $\tau-1$ observed in the data, $\varphi_{i g \tau-1} \Rightarrow \widehat{\varphi}_{i g \tau}$.

3. Keep only foreign items' shares, and aggregate them within a group $g$ to obtain the group-specific foreign share $\Rightarrow \widehat{\varphi}_{g \tau}^{F}=\sum_{i \in I_{g, \tau}^{F}} \widehat{\varphi}_{i g \tau}$.

The predicted q-on-q within-group expenditure switching is then cumulated into a y-on-y measure by summing up four consecutive quarters in order to eliminate seasonality issues:

$$
\left(s_{t}^{F-s_{k}^{F}}\right)^{\text {Within }}=\sum_{\tau=k}^{t} \sum_{g} s_{g \tau-1}\left(\widehat{\varphi}_{g \tau}^{F}-\varphi_{g \tau-1}^{F}\right),
$$

where $k=t-3$. 
The following steps provide more details on the procedure, as well as how we calculate analytical standard errors for the predicted aggregate within-group expenditure switching between $k$ and $t$. Note that we also construct a data counterpart, $\left(s_{t}^{F}-s_{k}^{F}\right)^{\text {Within }}=$ $\sum_{\tau=k}^{t} \sum_{g} s_{g \tau-1}\left(\varphi_{g \tau}^{F}-\varphi_{g \tau-1}^{F}\right)$, to compare to the predicted values. ${ }^{50}$

\section{E.1 Step 1}

We use the estimated coefficient to predict the growth rates of item shares at any quarter $\tau$ :

$$
\widehat{\Delta \ln \varphi}_{i g \tau}=\widehat{\beta}_{g} Z_{i g \tau}
$$

where $\widehat{\beta}_{g} \sim \mathrm{N}\left\{\beta_{g}, \Sigma_{g}\right\}$, and we have estimates of $\Sigma_{g}, \widehat{\Sigma}_{g}$, which are based on clustering.

\section{E.2 Step 2}

Next, we take actual data at time $\tau-1$ and use (E.3) to predict the within-group share of item $i$ at any quarter $\tau$ :

$$
\widehat{\varphi}_{i g \tau}=\left(1+\widehat{\beta}_{g} Z_{i g \tau}\right) \varphi_{i g \tau-1}
$$

Note that the randomness of $\widehat{\varphi}_{i g \tau}$ comes from $\widehat{\beta}_{g}$.

\section{E.3 Step 3}

We next simply aggregate (E.4) for each group $g$ for only foreign items to obtain a product group's predicted foreign share:

$$
\begin{aligned}
\widehat{\varphi}_{g \tau}^{F} & =\sum_{i \in I_{g \tau / \tau-1}^{F}}\left(1+\widehat{\beta}_{g} Z_{i g \tau}\right) \varphi_{i g \tau-1} \\
& =\sum_{i \in I_{g \tau / \tau-1}^{F}} \varphi_{i g \tau-1}+\sum_{i \in I_{g \tau / \tau-1}^{F}}\left(\widehat{\beta}_{g} Z_{i g \tau}\right) \varphi_{i g \tau-1} \\
& =\varphi_{g \tau-1}^{F}+\sum_{i \in I_{g \tau / \tau-1}^{F}}\left(\widehat{\beta}_{g} Z_{i g \tau}\right) \varphi_{i g \tau-1} .
\end{aligned}
$$

Note here that the foreign share for a given group is going to depend on the previous period's observed foreign share. Further, for the next step, define $Q_{g \tau}^{F} \equiv \sum_{i \in I_{g \tau / \tau-1}^{F}} Z_{i g \tau} \varphi_{i g \tau-1}$.

\footnotetext{
${ }^{50}$ This measure is not identical to the within expenditure switching presented in Figure 5, but the two series are very similar.
} 


\section{E.4 Step 4}

Calculate the model predicted expenditure switching between periods $\tau$ and $\tau-1$ :

$$
\left(\widehat{s_{\tau}^{F-s_{\tau-1}^{F}}}\right)^{\text {Within }}=\sum_{g} s_{g \tau-1}\left(\widehat{\varphi}_{g \tau}^{F}-\varphi_{g \tau-1}^{F}\right)
$$

which we then aggregate over four consecutive quarters to arrive at predicted year-on-year expenditure switching:

$$
\left(\widehat{s}_{t}^{F-s_{k}^{F}}\right)^{\text {Within }}=\sum_{\tau=k}^{t} \sum_{g} s_{g \tau-1}\left(\widehat{\varphi}_{g \tau}^{F}-\varphi_{g \tau-1}^{F}\right)
$$

where $k=t-3$.

\section{E.5 Aggregate Variance}

We are interested in calculate the variance of (E.7):

$$
\operatorname{Var}\left\{\sum_{\tau=k}^{t} \sum_{g} s_{g \tau-1} \widehat{\varphi}_{g \tau}^{F}\right\}=\sum_{\tau=k}^{t} \operatorname{Var}\left\{X_{\tau}\right\}+2 \sum_{p \neq \tau} \sum_{\tau=k}^{t} \operatorname{Cov}\left\{X_{\tau}, X_{p}\right\},
$$

where $X_{\tau}=\sum_{g} s_{g \tau-1} \widehat{\varphi}_{g \tau}^{F}$, and $X_{p}=\sum_{g} s_{g p-1} \widehat{\varphi}_{g p}^{F}$, or

$$
\begin{aligned}
\operatorname{Var}\left\{\sum_{\tau=k}^{t} \sum_{g} s_{g \tau-1} \widehat{\varphi}_{g \tau}^{F}\right\}= & \sum_{\tau=k}^{t} \sum_{n} \sum_{g} s_{g \tau-1}^{2}\left(Q_{g \tau}^{F}\right)^{2} \operatorname{Cov}\left\{\widehat{\beta}_{g}, \widehat{\beta}_{n}\right\} \\
& +2 \sum_{p \neq \tau} \sum_{\tau=k}^{t} \sum_{n} \sum_{g} s_{g \tau-1} s_{g p-1} Q_{g \tau}^{F} Q_{n p}^{F} \operatorname{Cov}\left\{\widehat{\beta}_{g}, \widehat{\beta}_{n}\right\} \\
= & \sum_{p=k}^{t} \sum_{\tau=k}^{t} \sum_{n} \sum_{g} s_{g \tau-1} s_{g p-1} Q_{g \tau}^{F} Q_{n p}^{F} \operatorname{Cov}\left\{\widehat{\beta}_{g}, \widehat{\beta}_{n}\right\}
\end{aligned}
$$


Table A1. CES and Non-Homothetic Models' Heterogeneous Coefficient Regressions: Weighted-Mean Estimates

\begin{tabular}{lccccc}
\hline \hline & & & & & \\
& $(1)$ & $(2)$ & $(3)$ & $(4)$ & $(5)$ \\
\cline { 2 - 6 }$\Delta \ln \left(p_{i g t} / P_{g t}\right)$ & -2.938 & -2.949 & -2.956 & -2.971 & -3.032 \\
& $(0.028)$ & $(0.027)$ & $(0.027)$ & $(0.028)$ & $(0.027)$ \\
$\ln \bar{p}_{i g} \times \Delta \ln C_{t}$ & & 1.701 & 1.531 & 1.740 & 1.581 \\
& & $(0.140)$ & $(0.155)$ & $(0.154)$ & $(0.143)$ \\
$\ln \bar{p}_{i g} \times\left(\Delta \ln C_{t}\right)^{2}$ & & & -3.576 & & \\
& & & $(2.366)$ & & \\
Observations & 372,484 & 372,484 & 372,484 & 372,484 & 372,484 \\
Group $\times$ time F.E. & 7,344 & 7,344 & 7,344 & - & 7,344 \\
Group $\times$ origin $\times$ time F.E. & - & - & - & 11,638 & - \\
Item F.E. & - & - & - & - & 26,555 \\
$R^{2}$ & 0.143 & 0.146 & 0.145 & 0.179 & 0.319 \\
\hline
\end{tabular}

Notes: This table presents weighted means of the coefficients of regression model (9), and is an extension of the heterogeneous coefficient regressions reported in the main regression table Table 6 , where columns (1) and (2) are identical to the results in the main text. The weights are a product group's share of total expenditures over the sample period. Column (1) presents the price coefficients for the CES model; columns (2) and (3) present the price and income coefficients, for the non-homothetic model with and without a quadratic term for income, respectively. These specifications are run with product group $\times$ time fixed effects. Columns (4) and (5) run the baseline NH model with product group $\times$ origin $\times$ time or item-level fixed effects, respectively. Standard errors clustered at the item level are in parentheses. 
Table A2. CES and Non-Homothetic Pooled Regression Estimates: Baseline

\begin{tabular}{|c|c|c|c|c|c|}
\hline & $(1)$ & $(2)$ & $(3)$ & $(4)$ & $(5)$ \\
\hline$\Delta \ln \left(p_{i g t} / P_{g t}\right)$ & $\begin{array}{l}-2.390 \\
(0.020)\end{array}$ & $\begin{array}{l}-2.391 \\
(0.020)\end{array}$ & $\begin{array}{c}-2.391 \\
(0.020)\end{array}$ & $\begin{array}{l}-2.413 \\
(0.020)\end{array}$ & $\begin{array}{l}-2.530 \\
(0.020)\end{array}$ \\
\hline $\ln \bar{p}_{i g} \times \Delta \ln C_{t}$ & & $\begin{array}{c}1.104 \\
(0.066)\end{array}$ & $\begin{array}{c}1.122 \\
(0.075)\end{array}$ & $\begin{array}{c}1.030 \\
(0.070)\end{array}$ & $\begin{array}{c}0.973 \\
(0.067)\end{array}$ \\
\hline $\ln \bar{p}_{i g} \times\left(\Delta \ln C_{t}\right)^{2}$ & & & $\begin{array}{c}0.540 \\
(1.041)\end{array}$ & & \\
\hline Observations & 372,484 & 372,484 & 372,484 & 372,484 & 372,484 \\
\hline Group $\times$ time F.E. & 7,344 & 7,344 & 7,344 & - & 7,344 \\
\hline Group $\times$ origin $\times$ time F.E. & - & - & - & 11,638 & - \\
\hline Item F.E. & - & - & - & - & 26,555 \\
\hline$R^{2}$ & 0.120 & 0.120 & 0.120 & 0.154 & 0.295 \\
\hline
\end{tabular}

Notes: This table presents coefficients of the pooled estimation of regression model (9), and correspond to the heterogeneous coefficient regressions reported in the main regression table Table 6, and Table A1. Column (1) presents the price coefficients for the CES model; columns (2) and (3) present the price and income coefficients, for the non-homothetic model with and without a quadratic term for income, respectively. These specifications are run with product group $\times$ time fixed effects. Columns (4) and (5) run the baseline $\mathrm{CES}$ and NH models with product group $\times$ origin $\times$ time fixed. Standard errors clustered at the item level are in parentheses. 
Table A3. CES and Non-Homothetic Pooled Regression Estimates: Instrumental Variables

Panel A: Foreign Items

\begin{tabular}{|c|c|c|c|c|}
\hline & \multicolumn{2}{|r|}{$C E S$} & \multicolumn{2}{|r|}{ NH } \\
\hline & (1) & $(2)$ & $(3)$ & (4) \\
\hline & OLS & IV & OLS & IV \\
\hline$\Delta \ln \left(p_{i g t} / P_{g t}\right)$ & -2.410 & -4.177 & -2.410 & -3.949 \\
\hline & $(0.045)$ & $(0.628)$ & $(0.045)$ & $(0.621)$ \\
\hline $\ln \bar{p}_{i g} \times \Delta \ln C_{t}$ & & & 0.875 & 0.873 \\
\hline & & & $(0.141)$ & $(0.145)$ \\
\hline Observations & 90,323 & 90,323 & 90,323 & 90,323 \\
\hline Group $\times$ time F.E. & 4,468 & 4,468 & 4,468 & 4,468 \\
\hline$R^{2}$ & 0.198 & 0.158 & 0.198 & 0.168 \\
\hline Instrument & - & NER \& Quality & - & NER \& Quality \\
\hline Kleibergen-Paap F-stat & - & 13.18 & - & 13.20 \\
\hline
\end{tabular}

Panel B: Subset of Domestic Items

\begin{tabular}{|c|c|c|c|c|}
\hline & \multicolumn{2}{|r|}{$C E S$} & \multicolumn{2}{|r|}{$N H$} \\
\hline & $(1)$ & $(2)$ & $(3)$ & $(4)$ \\
\hline & OLS & IV & OLS & IV \\
\hline$\Delta \ln \left(p_{i g t} / P_{g t}\right)$ & $\begin{array}{l}-2.547 \\
(0.074)\end{array}$ & $\begin{array}{l}-2.712 \\
(0.399)\end{array}$ & $\begin{array}{l}-2.551 \\
(0.074)\end{array}$ & $\begin{array}{l}-2.741 \\
(0.402)\end{array}$ \\
\hline $\ln \bar{p}_{i g} \times \Delta \ln C_{t}$ & & & $\begin{array}{c}0.867 \\
(0.416)\end{array}$ & $\begin{array}{c}0.921 \\
(0.431)\end{array}$ \\
\hline Observations & 19,119 & 19,119 & 19,119 & 19,119 \\
\hline Group $\times$ time F.E. & 2,060 & 2,060 & 2,060 & 2,060 \\
\hline$R^{2}$ & 0.458 & 0.457 & 0.458 & 0.457 \\
\hline Instruments & - & Estonian prices & - & Estonian prices \\
\hline Kleibergen-Paap F-stat & - & 104.1 & - & 102.8 \\
\hline
\end{tabular}

Notes: This table presents coefficients of the pooled estimation of regression model (9), instrumenting for the change in the relative price. Panel A uses data for imported items from non-euro countries, and instruments using six lags of exchange rate changes, and these changes interacted with an item's average unit value (relative to the group price index). Panel B uses a subset of domestic items that are also sold in Estonia, and instruments using contemporaneous values of Estonian items' price changes. These specifications are run with product group $\times$ time fixed effects. Standard errors clustered at the item level are in parentheses. 


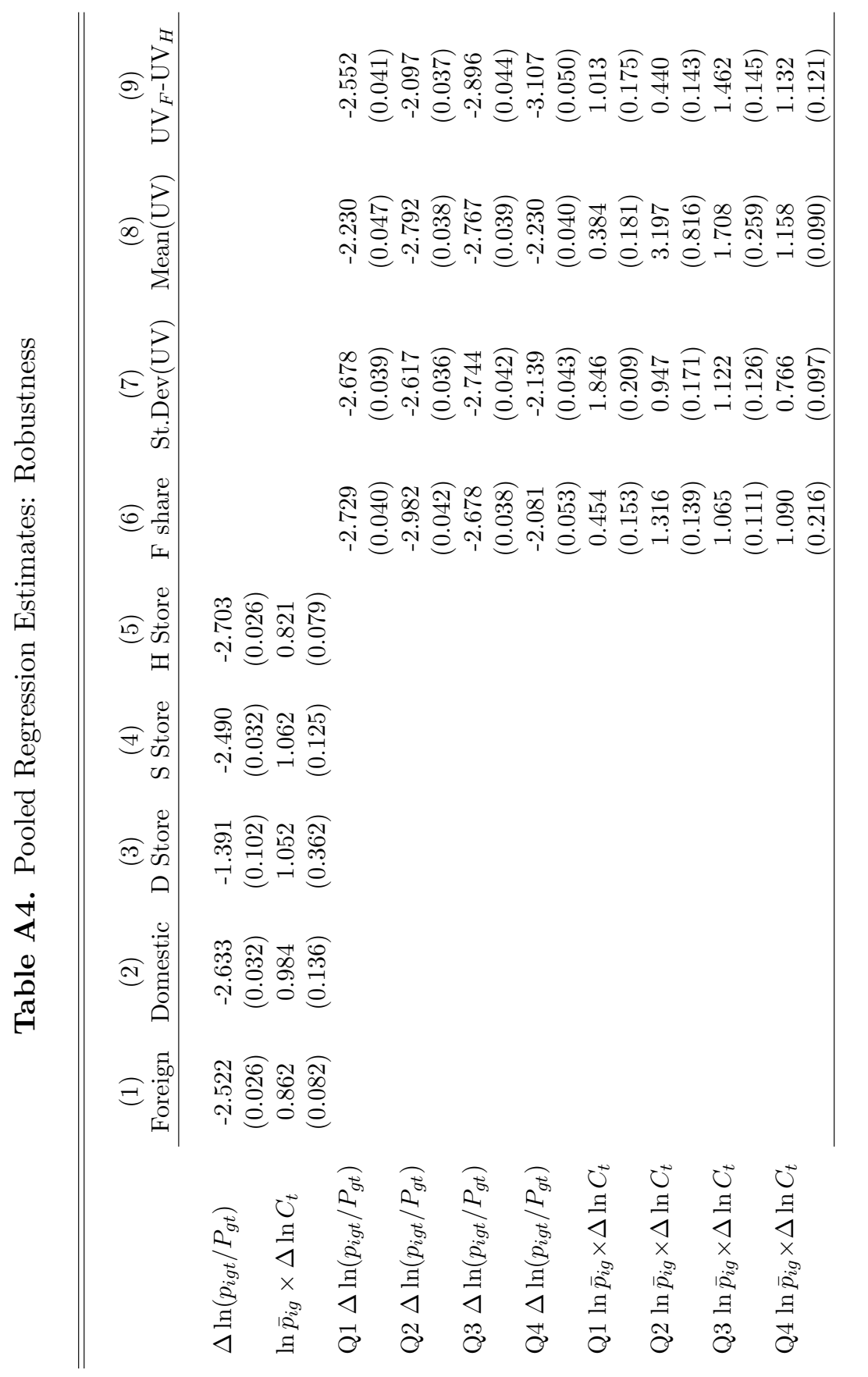

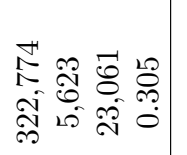

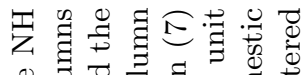

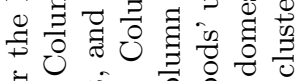

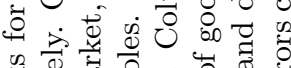

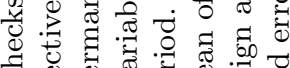

ơ

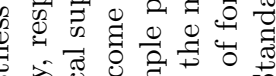

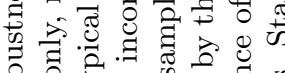

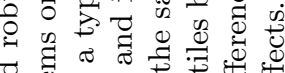

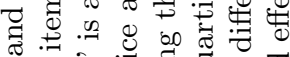

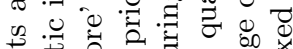

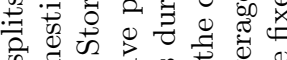

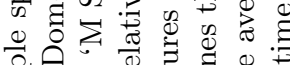

青虽

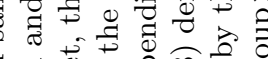

아의

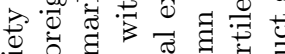

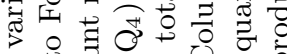

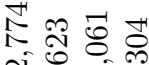

ชิ 12 .

可 눙

ऽ. 专

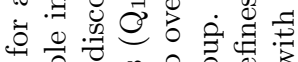

ब. द्वे

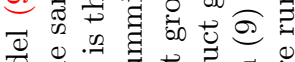

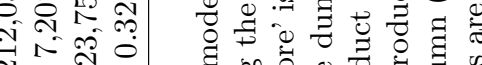

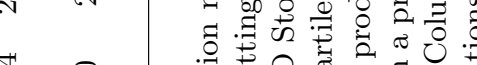

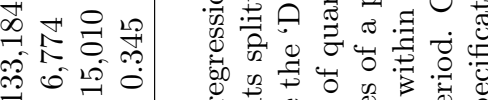

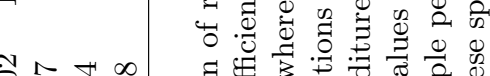

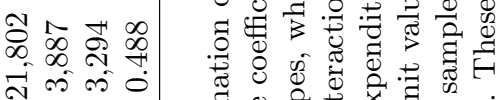

员 0 同

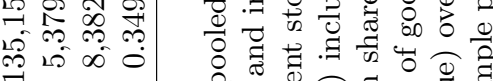

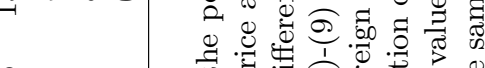

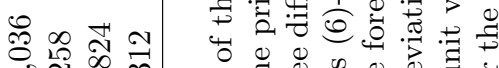

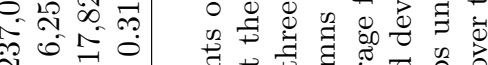

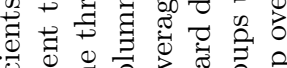

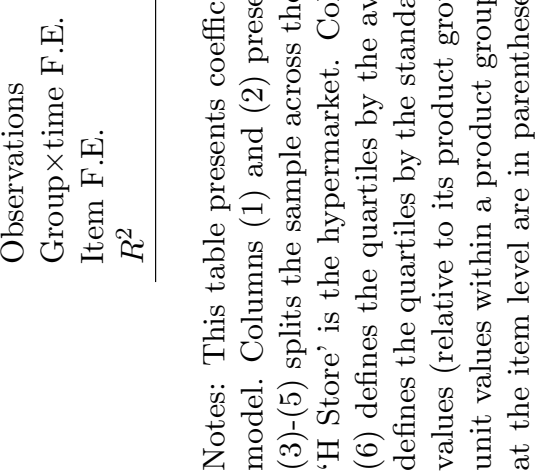


Table A5. Within-Group Predicted Expenditure Switching for OLS and IV Pooled Estimates

\begin{tabular}{|c|c|c|c|}
\hline & \multicolumn{3}{|c|}{ Panel A: Baseline OLS } \\
\hline & $\begin{array}{l}(1) \\
\text { Coef. }\end{array}$ & $\begin{array}{c}(2) \\
\text { Predicted ES }\end{array}$ & $\begin{array}{c}(3) \\
\text { Share }\end{array}$ \\
\hline Price & $\begin{array}{l}-2.391 \\
(0.020)\end{array}$ & $\begin{array}{c}-0.010 \\
(0.000)\end{array}$ & $\begin{array}{c}0.221 \\
(0.010)\end{array}$ \\
\hline Income & $\begin{array}{c}1.104 \\
(0.066)\end{array}$ & $\begin{array}{l}-0.037 \\
(0.002)\end{array}$ & $\begin{array}{c}0.779 \\
(0.010)\end{array}$ \\
\hline Total & - & $\begin{array}{l}-0.047 \\
(0.002)\end{array}$ & \\
\hline
\end{tabular}

\section{Panel B: Exchange Rate-Quality IV}

\begin{tabular}{lccc} 
& $(1)$ & $(2)$ & $(3)$ \\
& Coef. & Predicted ES & Share \\
\cline { 2 - 4 } Price & -3.949 & -0.017 & 0.371 \\
& $(0.621)$ & $(0.003)$ & $(0.054)$ \\
Income & 0.873 & -0.029 & 0.629 \\
\multirow{2}{*}{ Total } & $(0.145)$ & $(0.005)$ & $(0.054)$ \\
& - & -0.046 & \\
\hline
\end{tabular}

Notes: This table presents predicted within-group expenditure switching ('Predicted ES') for OLS and IV coefficient estimates. Panel A uses the baseline OLS coefficients from column (3) of Table A2, while Panel B uses the IV estimates based on the foreign subsample from column (4) of Table A3. Column (1) contains the estimated coefficients, column (2) shows the predicted expenditure switching, and column (3) presents the share of expenditure switching due to the price and income effects. The following values, corresponding to the crisis period and foreign items, were used to predict expenditure switching: $\Delta \ln \left(p_{i g t} / P_{g t}\right)=0.004$; $\Delta \ln C_{t}=-0.133$, and $\ln \bar{p}_{i g}=0.25$. Standard errors clustered at the item level are in parentheses. 
Figure A1. Domestic and Import Goods: Continuing, Entry, and Exit

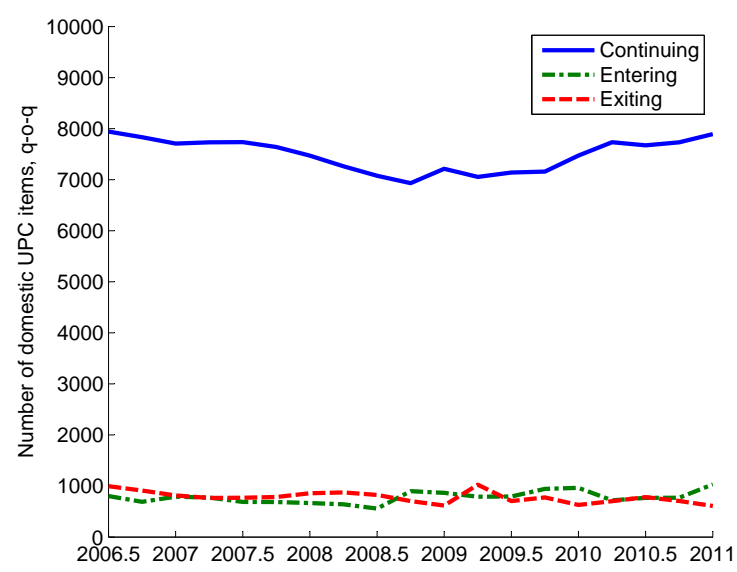

(a) Domestic Count

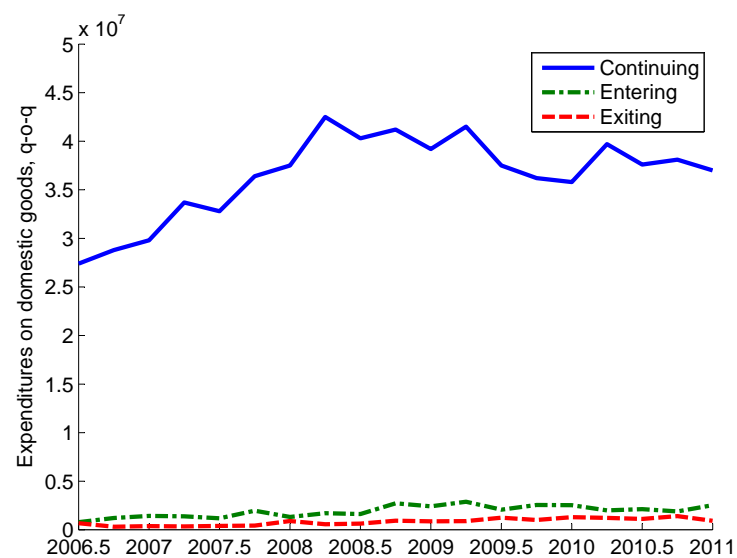

(c) Domestic Expenditure

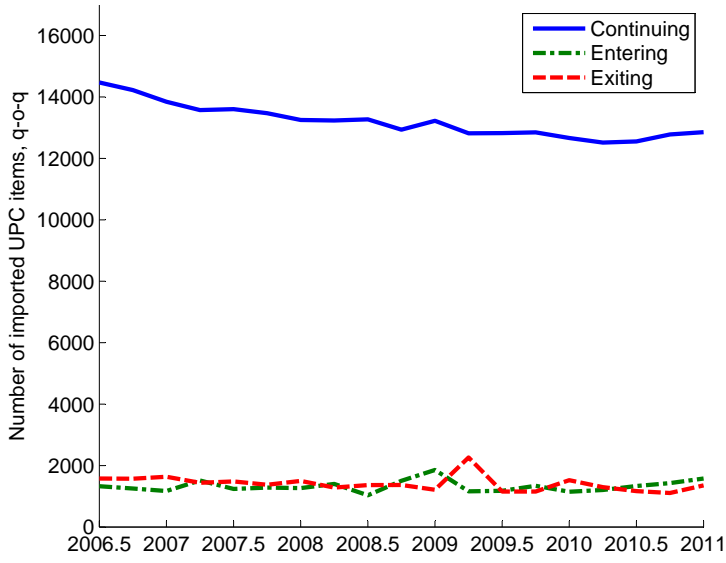

(b) Foreign Count

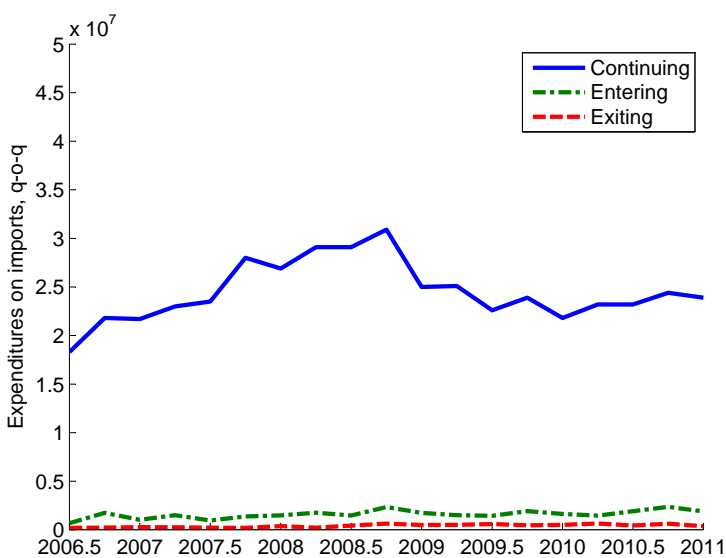

(d) Foreign Expenditure

Notes: This figure plots the time series of items that (i) continue, (ii) enter, and (iii) exit from one quarter to the next for domestic and foreign goods. The top two panels present the count of UPCs, while the bottom two panels present total expenditures on the types of goods. 
Figure A2. Growth Rate of Expenditure Switching: Total and Intensive and Extensive Margins

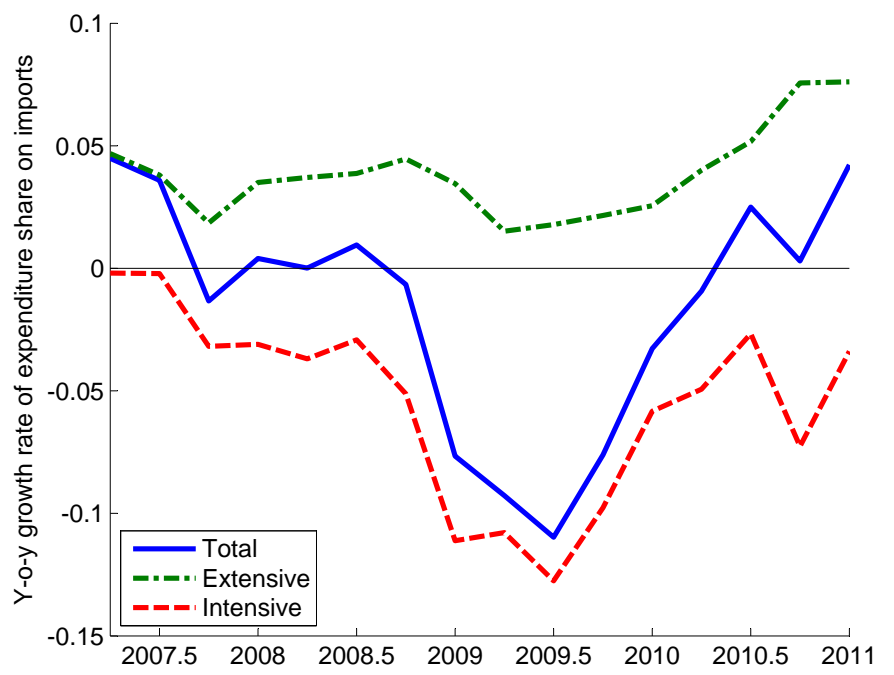

Notes: This figure plots the growth rate of the total expenditure share on imported goods, as well as the contribution to growth due to changes for continuing goods - the intensive margin - and due to net entry and exit of goods - the extensive margin. Growth rates are calculated using quarterly data and are then accumulated over a four-quarter overlapping rolling window.

Figure A3. Decomposition of Within Expenditure Switching: Within Store Type and Across Store Type Components

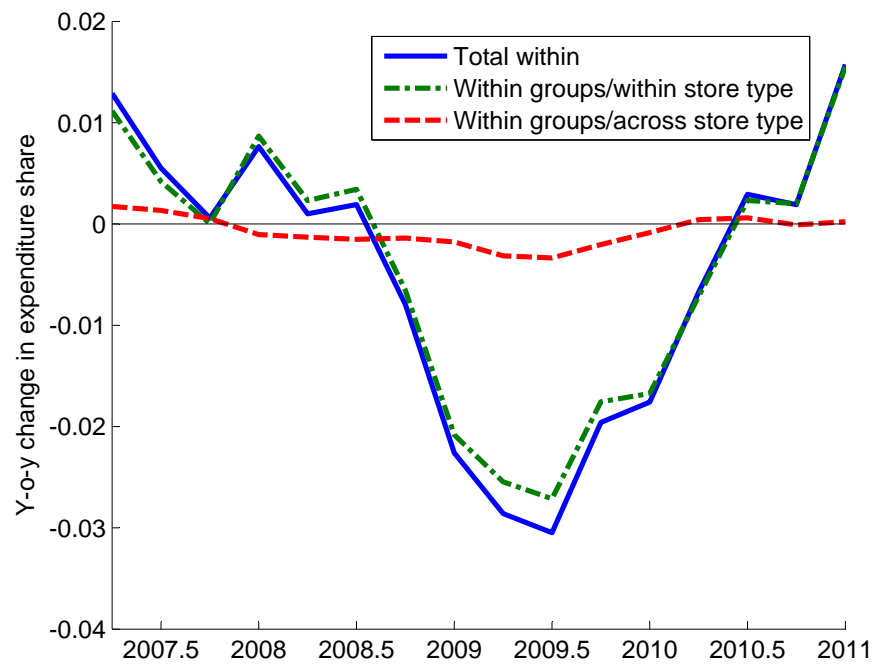

Notes: This figure decomposes total expenditure switching within 4-digit product groups into two subcomponents: (i) expenditure switching within product groups and within store types, and (ii) expenditure switching within product groups but across store types. Changes in expenditure shares are expressed as y-o-y changes, based on quarterly data. 